\title{
ER stress activates immunosuppressive network: implications for aging and Alzheimer's disease
}

\author{
Antero Salminen ${ }^{1} \cdot$ Kai Kaarniranta ${ }^{2,3} \cdot$ Anu Kauppinen $^{4}$
}

Received: 7 January 2020 / Revised: 24 March 2020 / Accepted: 26 March 2020 / Published online: 11 April 2020

(C) The Author(s) 2020

\begin{abstract}
The endoplasmic reticulum (ER) contains stress sensors which recognize the accumulation of unfolded proteins within the lumen of ER, and subsequently these transducers stimulate the unfolded protein response (UPR). The ER sensors include the IRE1, PERK, and ATF6 transducers which activate the UPR in an attempt to restore the quality of protein folding and thus maintain cellular homeostasis. If there is excessive stress, UPR signaling generates alarmins, e.g., chemokines and cytokines, which activate not only tissue-resident immune cells but also recruit myeloid and lymphoid cells into the affected tissues. ER stress is a crucial inducer of inflammation in many pathological conditions. A chronic low-grade inflammation and cellular senescence have been associated with the aging process and many age-related diseases, such as Alzheimer's disease. Currently, it is known that immune cells can exhibit great plasticity, i.e., they are able to display both pro-inflammatory and anti-inflammatory phenotypes in a context-dependent manner. The microenvironment encountered in chronic inflammatory conditions triggers a compensatory immunosuppression which defends tissues from excessive inflammation. Recent studies have revealed that chronic ER stress augments the suppressive phenotypes of immune cells, e.g., in tumors and other inflammatory disorders. The activation of immunosuppressive network, including myeloid-derived suppressor cells (MDSC) and regulatory T cells (Treg), has been involved in the aging process and Alzheimer's disease. We will examine in detail whether the ER stress-related changes found in aging tissues and Alzheimer's disease are associated with the activation of immunosuppressive network, as has been observed in tumors and many chronic inflammatory diseases.
\end{abstract}

Keywords Ageing $\cdot$ Immunometabolism $\cdot$ Immunosenescence $\cdot$ Immunosuppression $\cdot$ Inflammaging $\cdot$ Neurodegeneration

\section{Introduction}

Host defence is based on diverse sensor systems which recognize different harmful stimuli and are able to induce specific adaptive responses in order to restore cellular homeostasis. Oxidative, proteotoxic, and metabolic stresses as well as

Antero Salminen

antero.salminen@uef.fi

1 Department of Neurology, Institute of Clinical Medicine, University of Eastern Finland, P.O. Box 1627, FI-70211 Kuopio, Finland

2 Department of Ophthalmology, Institute of Clinical Medicine, University of Eastern Finland, P.O. Box 1627, FI-70211 Kuopio, Finland

3 Department of Ophthalmology, Kuopio University Hospital, P.O. Box 100, FI-70029 Kuopio, Finland

4 School of Pharmacy, Faculty of Health Sciences, University of Eastern Finland, P.O. Box 1627, FI-70211 Kuopio, Finland hypoxia and impaired calcium balance are common inducers of endoplasmic reticulum (ER) stress. There are three branches of transmembrane ER sensors which detect disturbances in the quality of protein folding in the ER [1]. These are the following: (i) inositol-requiring protein 1 (IRE1), (ii) protein kinase RNA-like ER kinase (PERK), and (iii) activating transcription factor 6 (ATF6) which recognize the accumulation of unfolded and misfolded proteins in the lumen of ER (Fig. 1). Subsequently, these transducers trigger downstream cytoplasmic signaling cascades which induce the unfolded protein response (UPR). The function of UPR is to restore the quality of protein folding and protect cells against stress-induced injuries. If there is an overwhelming stress, UPR signaling can activate the processes that trigger apoptotic cell death. Moreover, it is crucial that UPR signaling is also able to generate alarmins, e.g., chemokines and cytokines, which recruit inflammatory cells into tissues suffering excessive stress. Chronic ER stress, defects in proteostasis, and inflammation are the typical features of many human diseases 


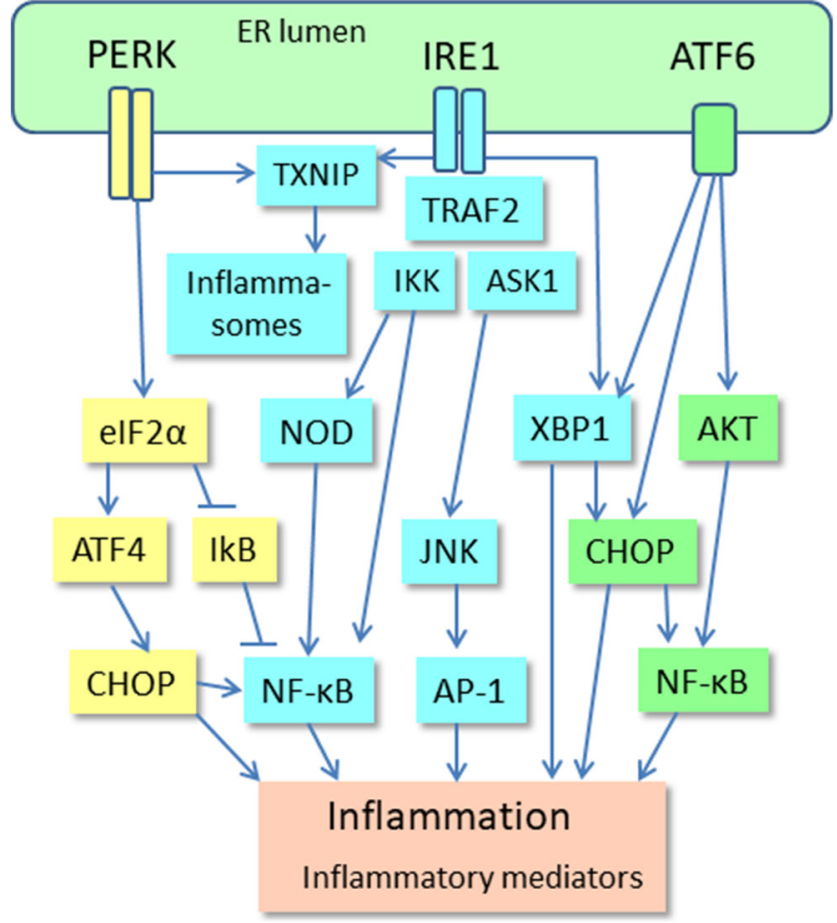

Fig. 1 ER stress evokes inflammatory responses via the activation of three branches of ER stress sensors. PERK, IRE1, and ATF6 signaling pathways induce the expression of inflammatory mediators by activating AP-1, CHOP, and NF- $\mathrm{KB}$ transcription factors. IRE1 and PERK signaling can also trigger TXNIP signaling which activates inflammasomes. There are several review articles depicting the UPR pathways more thoroughly, both the basic pathways $[1,17,26,27,31]$ and those related to inflammation and immunity $[16,81,82]$. Abbreviations: AKT, protein kinase B; AP-1, activator protein 1; ASK1, apoptosis signal-regulating kinase 1; ATF, activating transcription factor; CHOP, CCAAT-enhancer-binding protein homologous protein; eIF $2 \alpha$, eukaryotic initiation factor $2 \alpha$; ER, endoplasmic reticulum; I $\mathrm{KB}$, nuclear factor of kappa light polypeptide gene enhancer in B-cells inhibitor; IKK, IKB kinase; IRE1, inositolrequiring protein 1 ; JNK, c-Jun $\mathrm{N}$-terminal kinase; NF- $\mathrm{KB}$, nuclear factor- $\mathrm{kB}$; NOD, nucleotide-binding oligomerization domain-containing protein; PERK, protein kinase RNA-like ER kinase; TRAF2, TNF receptor-associated factor 2; TXNIP, thioredoxin-interacting protein; XBP1, X-box binding protein 1

including metabolic diseases, inflammatory diseases, cancers, and several age-related diseases, such as atherosclerosis and neurodegenerative diseases $[2,3]$. Currently, it seems that chronic ER stress is actually the major contributor to chronic inflammation rather than simply a consequence of inflammation.

Recently, it has been observed that both myeloid and lymphoid cells are able to exhibit extensive plasticity; for instance many immune cells display both the pro-inflammatory and anti-inflammatory phenotypes in a context-dependent manner, e.g., after infiltration of these cells into stressed tissues. The immune suppressive phenotypes are commonly called regulatory subtypes since they can inhibit the functions of immune effector cells $[4,5]$. The best characterized immunosuppressive subtypes of myeloid cells include immature myeloidderived suppressor cells (MDSC) as well as regulatory macrophages (Mreg/M2c) and dendritic cells (DCreg/ tolDC). Correspondingly, regulatory $\mathrm{T}$ (Treg) and B (Breg) cells are immunosuppressive lymphoid cells. Inflammatory mediators are potent enhancers of immunosuppressive phenotypes, and chronic inflammation is generally associated with a compensatory immunosuppressive state. Recent studies have demonstrated that ER stress has a key role in the immunosuppression induced by the inflamed tumor microenvironment [6-8]. In fact, ER stress can be transmitted from the host tissue into recruited immune cells in inflamed tissues [8-10]. There is convincing evidence that ER stress induces the polarization of immune cells toward immunosuppressive phenotypes [8, 11]. In pathological conditions, it seems that the ER stress of host tissue can recruit immune cells and provoke inflammation in the acute phase, whereas in chronic inflammatory states, the ER stress activates immunosuppression to try to dampen excessive inflammation. Immunosuppression has many detrimental effects in persistent inflammatory disorders leading to immune deficiencies, cellular senescence, and tissue degeneration.

A chronic low-grade inflammation and impaired proteostasis are two hallmarks of the aging process and Alzheimer's disease (AD). ER stress is closely associated with both aging and $\mathrm{AD}$ pathology (see below). For instance, ER stress is connected to the generation of cellular senescence [12-14]. The number of senescent cells progressively increases with aging. It is also known that ER stress is evident in neurons of human AD patients [15]. There is substantial evidence that the immunosuppressive network has become activated in the aging process and AD pathology (see below). Given that both the aging process and $\mathrm{AD}$ are associated with chronic inflammation and impaired proteostasis, it seems likely that ER stress induces immunosuppression which disturbs the maintenance of tissue homeostasis not only during aging but also in $\mathrm{AD}$ pathology.

\section{ER stress stimulates UPR signaling}

The UPR signaling pathways can restore cellular homeostasis by inducing either adaptive gene expression or provoking inflammation as an alarming response to cell damage $[1,16]$. The primary function of UPR is (i) to halt protein synthesis, (ii) to induce the degradation of misfolded proteins, (iii) to increase the folding capacity by stimulating the expression of ER chaperones, and (iv) to prepare immune cells for harmful conditions and imminent cell injuries. Moreover, UPR signaling can function in the cooperation with autophagy, proteasomes, and mitochondria [17-19]. For instance, ER stress can increase the autophagic degradation of cytosolic proteins or induce the selective, receptor-mediated ER-phagy $[20,21]$. On the other hand, impaired autophagic degradation can trigger ER stress. Ghosh et al. [22] demonstrated that impaired autophagy in mouse adipose tissue from old animals 
was associated with increased ER stress and inflammation. The accumulation of misfolded proteins in the ER stimulates protein degradation via the ER-associated degradation (ERAD) pathway [17]. In the ERAD, misfolded proteins are ubiquitinated and subsequently transferred into the cytosol prior to proteasomal degradation. ER stress and UPR signaling also affect the crosstalk between ER and mitochondria at the mitochondria-associated membranes (MAM) where ER and mitochondria are physically in a close proximity [23]. This juxtaposition enhances calcium uptake into mitochondria, improves mitochondrial bioenergetic and redox balances, but it can also provoke apoptosis if there is excessive ER stress. There are many studies indicating that the disturbances in the MAM during ER stress might exert a significant role in the aging process and age-related diseases, such as Alzheimer's disease [24, 25].

The signaling mechanisms of UPR have been reviewed in detail elsewhere $[1,26]$. Briefly, the dimerization of IRE1 $\alpha$ transducers by unfolded proteins stimulates their protein kinase domains in the cytoplasm, inducing the binding of TRAF 2 protein to the IRE1 $\alpha$ complex. Subsequently, TRAF2 can activate the IKK and ASK1 protein kinases which trigger the activation of the NF- $\mathrm{KB}$ signaling and the JNK pathway, respectively [1]. The IRE1-TRAF2-IKK signaling stimulates the expression of NF-KB-driven inflammatory genes which consequently activate the immunosuppressive cells in conditions of chronic inflammation (Fig. 1). The IRE $1 \alpha$ protein also possesses endoribonuclease activity, cleaving mRNA molecules. The primary target of the regulated IRE1-dependent decay (RIDD) activity is the mRNA of Xbox binding protein-1 (XBP1) cleaving off one intron, thus activating the translation of XBP1 mRNA. IRE1 $\alpha$ can also split and degenerate distinct other mRNAs through the RIDD mechanism [27]. XBP1 is an important transcription factor which has many cell survival targets, but it can also evoke harmful effects. For instance, although it increases the expression of ER chaperones and ERAD components, it also exerts double-edged effects in glucose and lipid metabolism [28]. Interestingly, Martinez et al. [29] revealed that XBP1 improved mouse learning and memory processes by regulating memory-related genes, e.g., it increased the expression of BDNF. Recently, it has been revealed that the XBP1, an evolutionarily conserved protein, also has functions in cellular differentiation and cell cycle regulation which are not linked to ER stress [30].

The PERK transducer pathway is another signaling system which stimulates the UPR in ER stress [1,31]. The cytoplasmic protein kinase domain of PERK protein phosphorylates eukaryotic translation initiation factor- $2 \alpha(\mathrm{eIF} 2 \alpha)$ which inhibits protein synthesis and thus alleviates the pressure of unfolded proteins in the ER (Fig. 1). However, the phosphorylation of eIF2 kinase can enhance the translation of some stress-related mRNAs, e.g., activating transcription factor 4
(ATF4). Subsequently, ATF4 stimulates the expression of CHOP which in cooperation with ATF4 induces the expression of several autophagy genes [32]. The eIF2 $\alpha$ kinase can also stimulate NF- $\mathrm{KB}$ signaling [33], the major inducer of inflammatory genes. There are observations indicating that the activation of PERK-eIF $2 \alpha$ signaling has an essential role in memory deficits and Alzheimer's pathogenesis, e.g., eIF $2 \alpha$ activity elevates the expression of BACE1 and the production of $\beta$-amyloid [34]. The activation of PERK kinase also increases cell survival by activating NFE2L2 transcription factor which induces the expression of many cytoprotective genes [35]. In general, PERK signaling has beneficial effects to combat acute insults but its effects are detrimental if conditions become chronic, e.g., in mitochondrial quality control and metabolic responses.

The third branch of the UPR signaling pathways includes the ATF6 pathway and some other tissue-specific members of the bZIP family, e.g., CREBH found in liver and OASIS present in astrocytes [36]. ER stress triggers the translocation of ATF6 protein from the ER to the Golgi complex where its cytoplasmic domain becomes cleaved off by site 2 protease (S2P). The mature form of ATF6 is transferred into the nucleus where it acts as a transcription factor inducing not only stress-related genes, e.g., ER chaperones, ERAD components, autophagy genes, and CHOP factor but also the ER stressunrelated developmental genes [36, 37]. ATF6 factor exists in two opposing isoforms, i.e., ATF $6 \alpha$ is the transcriptional activator whereas ATF6 $\beta$ is the inhibitor. Interestingly, there is a close cross talk between different UPR signaling pathways. For instance, the PERK-ATF4 signaling increased the expression of ATF6 and enhanced its trafficking to the Golgi complex for the maturation process [38]. Correspondingly, ATF6 induced the expression of XBP1 mRNA which enhanced the signaling of IRE1 pathway [39].

\section{ER stress is associated with the aging process and Alzheimer's disease}

\section{ER stress in the aging process}

The aging process is associated with a number of conditions known to induce ER stress, e.g., deficiencies in autophagic and mitochondrial functions, disturbances in $\mathrm{Ca}^{2+}$ homeostasis, increased oxidative stress, and disorders in proteostasis and energy metabolism [40]. However, studies on the expression levels of UPR proteins, both transcription factors and ER chaperones, have revealed contradictory results, as reviewed in detail by Estebanez et al. [41]. This is not a surprise since the aging process is a progressive state in tissues with both acute and adaptive changes induced by a variety of endogenous stresses and alterations in the microenvironment, e.g., metabolic, hormonal, and inflammatory changes. The UPR signaling controls protein quality and maintains proteostasis, 
i.e., it downregulates protein synthesis through the PERKmediated phosphorylation of eIF $2 \alpha$ and thus it prevents the accumulation of unfolded proteins in stressed cells. The decline of protein synthesis is the most characteristic hallmark of the aging process $[40,42]$. However, PERK is not the only pathway which inhibits eIF $2 \alpha$ kinase but other stress kinases of integrated stress response (ISR) can inhibit protein synthesis [43]. The UPR transducers can recognize the intensity of ER stress and thus induce dose-dependent responses, i.e., mild stress stimulates adaptation and cell survival responses, whereas a severe stress threatening cell death alerts the inflammatory system and triggers signaling leading to apoptosis. This indicates that ER stress can induce the dose-dependent hormetic responses [44]. There are observations that a mild ER stress, e.g., induced by dietary restriction, increased the activity of UPR and expanded lifespan [45]. It is also known that the preceding mild ER stress ameliorated the inflammation of endothelial cells induced by harmful insults, e.g., LPS treatment or excessive cytokine exposure [46, 47]. These observations indicate that the transducers of ER stress have a crucial role in the regulation of both health span and life span.

Several studies have revealed that the age-related tissue atrophy and degeneration are associated with a decline in the amounts of many UPR-related transducers and chaperones, whereas the expression of ER stress linked CHOP was significantly increased with aging, e.g., in mouse cerebral cortex [48] and adipose tissues [49] as well as in the skeletal muscles [50], liver [51], and retina [52] of rats. CHOP is not only associated with apoptosis, it performs many immune and metabolic responses as well as having effects on adipocyte and osteoblast differentiation [53]. For instance, the ER stressinduced expression of CHOP stimulated inflammation and consequently provoked insulin resistance in mouse adipose tissue [54]. In addition to the promotion of inflammation, Thevenot et al. [11] demonstrated that CHOP has a crucial role in the activation of the immunosuppressive properties of MDSCs in an inflamed tumor site, a microenvironment where there is sustained ER stress. For instance, CHOP stimulated NF- $\mathrm{kB}$ signaling in chronic inflammatory diseases, e.g., nonalcoholic steatohepatitis [55]. It seems likely that the agerelated increase in the expression of CHOP is linked to inflammation rather than to apoptosis.

The aging process is associated with a progressively increasing accumulation of senescent cells in the tissues [ 40 , 56]. Senescent cells commonly possess a flat morphology, and their cell cycle is irreversibly arrested. Senescent cells undergo a chromatin remodeling process, and they display the gene activation of the tumor suppressor network, e.g., p16INK4a and p53. Senescent cells also secrete inflammatory mediators, a phenomenon called senescence-associated secretory phenotype (SASP) [57]. It is known that diverse cellular stresses activate NF- $\mathrm{KB}$ signaling which triggers the inflammatory phenotype of senescent cells [58]. There is convincing evidence that ER stress is associated with cellular senescence although ER stress could be either the driver or a counteracting consequence of the senescent phenotype [12]. However, several experiments in vitro have revealed that the ER stress-induced UPR is rather the inducer of cellular senescence and not only an outcome. Druelle et al. [13] reported that ATF $6 \alpha$ signaling controls many morphological aspects of the replicative senescence of human fibroblasts. The silencing of ATF $6 \alpha$ signaling could partly reverse the ER expansion and SASP of senescent cells. Recently, Cormenier et al. [14] demonstrated that the activation of ATF6 $\alpha$ maintained the senescent state of human fibroblasts by stimulating the COX2/PGE2 pathway. Most likely, ATF6 $\alpha$ signaling triggered the prostaglandin pathway through the activation of NF- $\mathrm{KB}$ signaling. Oubaha et al. [59] reported that the IRE1 branch of UPR stimulated the SASP-induced pathological form of angiogenesis in mouse retinopathy. The IRE1 $\alpha$ activation induced the senescent state in mouse retina by stimulating the RIDD pathway. The ribonuclease activity of IRE1 is an important mechanism in the control of protein synthesis, thus regulating cell homeostasis, e.g., in viral infections [27]. Currently, the selective elimination of senescent cells, called senolysis, is a promising therapeutic approach as it may alleviate the age-related diseases and thus extend life span [60].

\section{ER stress in Alzheimer's disease}

The pathogenesis of AD involves the gradual accumulation of $\beta$-amyloid plaques and neurofibrillary tangles in the human brain. The pathology of AD also involves clear evidence of inflammatory responses. The cause of impaired proteostasis in $\mathrm{AD}$ is still unknown although several hypotheses have been proposed. There is convincing evidence that ER stress is increased in human AD brains and might have a causative role in the pathogenesis of $\mathrm{AD}$ [61]. In their seminal study, Hoozemans et al. [62] demonstrated that the immunohistochemical staining of phosphorylated pPERK (activated) and UPR chaperone BiP/GRP78 were markedly increased in the neurons of temporal cortex and hippocampus in AD patients. In particular, the neurons of hippocampal CA1 and CA2 regions exhibited increased expression of pPERK and BiP/GRP78, whereas glial cells were not affected. Western blot assays revealed a clear correlation between the level of BiP/GRP78 and the amount of neurofibrillary tangles. In a later study, Hoozemans et al. [15] revealed that the UPR markers, i.e., pPERK, pIRE $1 \alpha$, and peIF $2 \alpha$, were clearly increased in the neurons containing the inclusions of granulovacuolar degeneration (GVD) in the hippocampus of AD patients. The most abundant pPERK staining was observed in those neurons which contained the diffuse localization of phospho-tau protein. They also observed that the increased staining of pPERK and pGSK-3 $\beta$, a tau kinase, co- 
localized in same hippocampal neurons which indicates that UPR might stimulate tau phosphorylation. Subsequent studies have revealed that soluble tau protein can interact with several ER proteins, thus disturbing the function of ER and inducing UPR [63, 64]. Abisambra et al. [63] demonstrated that soluble tau protein interacted with the proteins of the ERAD complex. They also revealed that this interaction impaired the function of ERAD and thus triggered ER stress and stimulated the UPR. ER stress has been associated with the early phase of other tauopathies [65]. Fouillet et al. [66] reported that a preceding mild ER stress, i.e., preconditioning, was neuroprotective in the Drosophila and mouse models of Parkinson disease since it promoted neuronal autophagy. It seems that ER stress can exert protective effects in the early phase of AD.

$\mathrm{AD}$ is a progressive neurodegenerative disease leading to cognitive impairment and dementia in its later phases. There are studies indicating that $\beta$-amyloid peptides can induce ER stress [67]. Moreover, ER stress increases the activities of BACE1 and $\gamma$-secretase and thus enhances the processing of APP [68, 69]. Interestingly, Zhu et al. [69] demonstrated that the level of membralin (TMEM259), a key component of ERAD, was strongly downregulated in the brains of AD patients. Given that nicastrin is the substrate of membralin, they demonstrated that the knockdown of membralin in mouse hippocampus induced ER stress and increased the level of nicastrin, a component of the $\gamma$-secretase complex. The membralin deficiency increased $\gamma$-secretase activity and induced $\beta$-amyloid pathology as well as aggravating synaptic/ memory deficits. It is not known whether the inhibition of ERAD by soluble tau (see above) might activate $\gamma$-secretase and induce AD pathology. There is abundant evidence emerging from animal experiments that the persistent activation of the PERK-eIF $2 \alpha$ branch has a significant role in the memory and cognitive impairments encountered in $\mathrm{AD}$ and other tauopathies [34]. The activation of PERK phosphorylates eIF $2 \alpha$ protein, thus inhibiting protein translation and consequently it disturbs the homeostasis of neurons. Duran-Aniotz et al. [70] observed that the level of activated IRE1 (pIRE1) correlated with the Braak stages of AD histopathology. Since it is known that IRE1 is activated in $A D$, these investigators generated a transgenic mouse model where the RNase domain of IRE1 was conditionally knocked out and then these mice were crossbreed with 5 XFAD mice which exhibit extensive AD pathology. The ablation of IRE1 caused a significant reduction in the deposition of plaques and fibrillary tangles and an amelioration of the cognitive impairment as compared with the corresponding pathology present in the 5xFAD mice. The PERK and IRE1 branches are connected to the activation of NF- $\mathrm{KB}$ signaling, a potential neuronal trigger of AD pathology [71]. It seems that chronic inflammation might enhance AD pathogenesis through the activation of UPR signaling.

\section{ER stress is a potent inducer of inflammation}

The ER stress-induced UPR not only maintains cellular homeostasis but it can also defend tissues in chronic disturbances by inducing apoptotic cell death or secreting alarmins which provoke an inflammatory response. In acute injuries, inflammation restores tissue homeostasis but prolonged inflammatory conditions stimulate the immunosuppressive network in an attempt to prevent excessive inflammatory damage in tissues (see below). There is clear evidence that ER stress can elicit inflammatory responses in many age-related diseases, e.g., atherosclerosis [72], hepatic steatosis [73], and age-related macular degeneration [74]. It seems that the activation of inflammasomes is involved in the crosstalk between ER stress and inflammatory responses in some diseases [72, 73]. Given its role as an alarming mechanism, ER stress stimulates the secretion of chemokines and cytokines which subsequently recruit immune cells into tissues and activate their inflammatory function [75]. There are several reports indicating that ER stress could induce the expression and secretion of C-C motif chemokine ligand 2 (CCL2/MCP-1) in different cell types [76]. In addition, ER stress can stimulate the expression of several other chemokines and colony stimulating factors (CSF), e.g., those of CXC motif ligand 3 (CXCL3) in human endothelial cells [77] and granulocyte macrophage CSF (GMCSF) in mouse adipocytes [78]. Kim et al. [79] demonstrated that the treatment with a CCR2 inhibitor reduced ER stress and lowered the inflammatory cytokine response in the steatotic liver of diabetic $\mathrm{db} / \mathrm{db}$ mice. The treatment downregulated the infiltration of inflammatory cells into mouse liver, and it also improved insulin sensitivity. Interestingly, Kapoor et al. [80] reported that the protein induced by MCP-1, MCPIP, inhibited the activation of NF-KB signaling in mouse macrophages and thus mediated the M2 polarization which represents the anti-inflammatory phenotype of macrophages. In aged tissues, the senescent cells displaying the SASP phenotype could be a significant source of chemokine/cytokine secretion [57]. Chemoattractant proteins are important inflammatory mediators induced by ER stress since they enhance the expansion of immune cells and regulate their recruitment into the tissues undergoing stress (Fig. 2).

ER stress can induce inflammatory responses through all three branches of UPR via different signaling pathways [71, 81-83] (Fig. 1). However, the activation of NF-KB signaling is the crucial, cooperative pathway inducing proinflammatory responses. The activation of IRE1 kinase recruits TRAF2 adaptor protein to bind to its cytoplasmic domain. Subsequently, this complex interacts with several proteins which decide cellular fate in times of ER stress. For instance, IKK and TANK bind to the IRE1/TRAF2 complex and subsequently activate NF- $\mathrm{KB}$ signaling. Moreover, ASK1 kinase, a binding partner for TRAF2, exerts several contextdependent effects on inflammation, autophagy, and apoptosis 


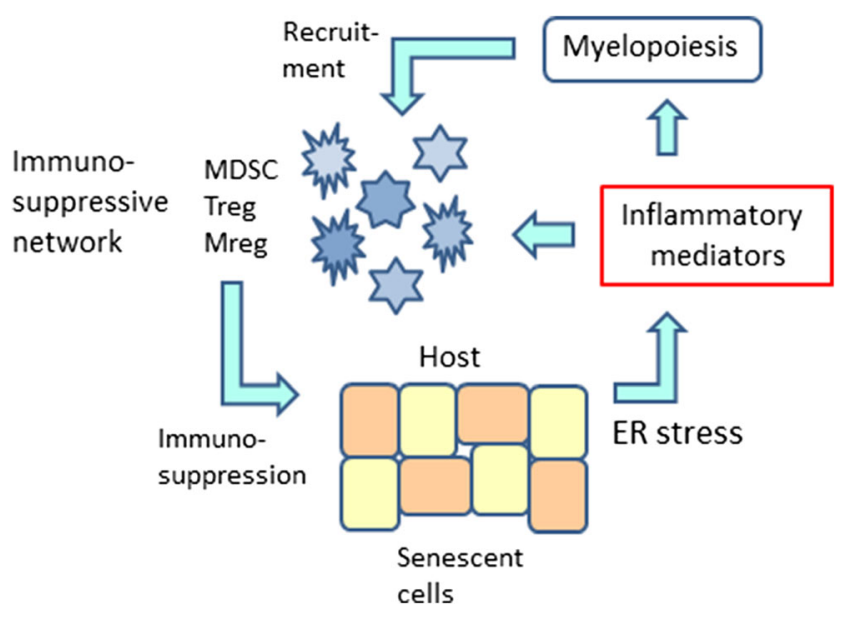

Fig. 2 A schematic presentation on the induction of immunosuppression by ER stress. The ER stress of host tissues, containing, e.g., senescent cells, stimulates the secretion of inflammatory mediators which consequently provoke myelopoiesis in the bone marrow. Increased numbers of myeloid cells will be recruited into lymphoid and peripheral tissues. Inflammatory mediators secreted by host tissues trigger ER stress in infiltrated immune cells and concurrently enhance their immunosuppressive properties. A continual immunosuppression in inflamed tissues further impairs the homeostasis of tissues, e.g., by impairing proteostasis and enhancing cellular senescence. This ER stress-provoked vicious cycle degenerates tissues with aging and brains in Alzheimer's disease. Abbreviations: MDSC, myeloid-derived suppressor cell; Mreg, regulatory macrophage; Treg, regulatory $\mathrm{T}$ cell.

[84]. ASK1 activates the expression of inflammatory genes through the JNK-AP-1 pathway (Fig. 1). Keestra-Gouder et al. [83] demonstrated that the two intracellular NOD receptors, NOD1 and NOD2, cooperate with the IRE1/TRAF2 complex to activate the NF- $\mathrm{KB}$ system in both macrophages and mouse tissues. These results indicated that NOD1/NOD2 signaling not only defends the organism against bacterial and viral infections but also protects cells from organelle stress. Kim et al. [85] reported that IRE1 $\alpha$ activation also controlled the production of cytokines with the cooperation of XBP1 and GSK- $3 \beta$ in mouse macrophages. Interestingly, the splicing of XBP1 was associated with the expression of TNF- $\alpha$, whereas the activation of GSK- $3 \beta$ increased the expression of IL- $1 \beta$. It seems that the inflammatory responses induced by ER stress are specific and probably cell-type-dependent processes.

There is convincing evidence that ER stress activates inflammasomes via different mechanisms [86, 87] (Fig. 1). Inflammasomes are cytoplasmic multimeric signaling complexes which act as a host-defence system against pathogens and a self-defence mechanism to respond to cellular danger signals. Inflammasomes activate caspase- 1 which cleaves the precursor forms of IL-1 $\beta$ and IL-18 into the mature, secreted pro-inflammatory cytokines. There are several types of inflammasomes containing different recognition sensors, e.g., NLRP1, NLRP3, and AIM2 [88]. It seems that ER stress can activate inflammasomes through different pathways in a context-dependent manner. Lerner et al. [86] demonstrated that the strong activation of IRE $1 \alpha$ rapidly increased the level of thioredoxin-interacting protein (TXNIP) which subsequently activated NLRP3 inflammasomes in mouse pancreatic $\beta$ cells (Fig. 1). They reported that IRE1 $\alpha$, a RIDDase enzyme, was able to split miR-17 which is a destabilizing factor of TXNIP mRNA. The activation of the IRE1 $\alpha$ TXNIP pathway promoted sterile inflammation and apoptosis in mouse $\beta$ cells. The PERK signaling can also induce the TXNIP-mediated activation of NLRP3 inflammasomes in mouse $\beta$ cells [89]. There are other mechanisms which can also trigger the ER stress-induced activation of NLRP3 inflammasomes. For instance, Robblee et al. [87] demonstrated that saturated fatty acids (SFA) induced ER stress in mouse and human macrophages. They reported that SFA activated IRE $1 \alpha$ and subsequently stimulated NLRP3 inflammasomes through their binding to membrane phosphatidylcholines. These studies indicate that inflammasomes are an important target of UPR signaling.

The PERK pathways have many important functions in the generation of inflammatory responses (Fig. 1). For instance, Guthrie et al. [90] revealed that PERK signaling especially enhanced the ER stress-induced cytokine and chemokine production, whereas it had less effect on the UPR-dependent survival and adaptive responses in mouse astrocytes. Meares et al. [91] demonstrated that the ER stress-induced PERK signaling activated the JAK1STAT3 pathway but it exerted a minor effect on the activation of NF- $\mathrm{KB}$ system in mouse astrocytes. Interestingly, STAT3 not only enhances pro-inflammatory reactions but it is the molecular hub of immunosuppressive responses in immune cells (see below). The robust activation of PERK and IRE1 by tunicamycin stimulated the expression of CHOP which induced pyroptosis, an inflammatory form of apoptosis, in mouse primary hepatocytes [92]. PERK stimulates CHOP signaling through the eIF $2 \alpha$-ATF 4 pathway [93] (Fig. 1). CHOP can augment inflammatory responses by activating the NF- $\mathrm{KB}$ system, e.g., in human primary hepatocytes [55]. The PERK-eIF $2 \alpha$ pathway can also activate NF- $\mathrm{KB}$ signaling by repressing the inhibitor of NF- $\mathrm{kB}$ (I $\kappa \mathrm{B}$ ) [94]. In addition, the activation of ATF6 branch can also stimulate the expression of inflammatory mediators via the AKT-NF-KB signaling [95] and the pathways between ATF6-XBP1-CHOP [1, 39] (Fig. 1). DeZwaan-McCabe et al. [96] revealed that the activation of CHOP in chronic inflammation promoted fibrosis and tumorigenesis in mouse liver. Conversely, the knockout of CHOP reduced the expression of inflammatory genes and prevented hepatic fibrosis and carcinogenesis. The activation of CHOP stimulates pro-inflammatory responses but it can also augment immunosuppressive properties [11], and thus in chronic inflammatory conditions, CHOP might control the balance between inflammation and immunosuppression. 


\section{Chronic inflammation is a hallmark of aging process and Alzheimer's disease}

The aging process is associated with a chronic low-grade inflammation, a state called inflammaging [97, 98]. The signs of augmented inflammation are not only present in peripheral tissues but also in bone marrow and lymphoid organs [99, 100]. Recently, Benayoun et al. [101] reported that the transcriptional trajectories of many innate immune pathways were significantly induced with aging across different tissues in humans and rodents. For instance, interferon- $\alpha / \gamma$ responses, JAK/STAT3 and NF-KB signaling, and complement pathways were clearly upregulated with aging. Interestingly, they also revealed that specific epigenomic states were associated with distinct age-related transcriptional profiles. Currently, it seems that there are different sources for the activation of inflammatory responses with aging. Interestingly, certain types of cellular stresses, e.g., ER stress and mitochondrial disturbances, are associated with the activation of the immune system (see above). In addition, the number of cells displaying senescent phenotype increases in both bone marrow and peripheral tissues [56]. Senescent nonimmune cells secrete inflammatory mediators [57] which might be a significant source of chemokines and cytokines in tissues with aging. The aging process also affects the hematopoietic stem cells expanding the lineages of myelopoiesis and downregulating those of lymphopoiesis [102]. This myeloid-biased shift promotes the generation of myeloid cells in bone marrow and subsequently enhances their recruitment into aging tissues.

The pathogenesis of $\mathrm{AD}$ involves a clear activation of microglia and astrocytes on the affected brain regions [103]. However, it needs to be clarified whether inflammatory changes are a cause of AD pathology or a consequence of the accumulation of $\beta$-amyloid plaques. $\beta$-Amyloid peptides are potent inducers of innate immune responses via different pattern recognition receptors [104]. Nonetheless, randomized clinical trials with nonsteroidal anti-inflammatory drugs (NSAID) as well as the amyloid-based immunotherapies have been unable to prevent the pathogenesis of $\mathrm{AD}[105,106]$. Inflammasomes are activated in the AD pathology which might generate an inflammatory microenvironment in the AD brain [107, 108]. Given that ER stress can activate inflammasomes, it is not surprising that neuronal ER stress could be a trigger for inflammation and consequently induce AD pathology [71]. There are also studies indicating that certain infections, especially herpes simplex virus, could create conditions of chronic inflammation and consequently $\mathrm{AD}$ pathology [109]. However, experiments with transgenic AD mice have indicated that $\beta$-amyloid does seem to exert crucial role in $\mathrm{AD}$ pathogenesis. Currently, it is evident that chronic inflammation induces an antagonistic anti-inflammatory response, i.e., an immunosuppressive state, which while preventing excessive inflammation, may unfortunately enhance AD pathology (see below).

\section{ER stress-induced immunosuppression}

\section{Inflamed microenvironment provokes immunosuppression}

There is substantial evidence that inflammatory mediators have a crucial role in the activation of the immunosuppressive network in affected tissues. In particular, studies on tumorigenesis have revealed that inflammation is the driving force behind the recruitment and activation of immunosuppressive cells in tumor sites $[110,111]$. MDSCs and Tregs are the most critical inducers of immunosuppression, i.e., they inhibit the functions of effector T cells and NK cells, and thus they allow tumor cells to escape immune surveillance. MDSCs are immature myeloid cells which are generated in myelopoiesis in bone marrow and subsequently secreted from bone marrow and recruited into extramedullary sites and inflamed tissues $[110,112]$. There are two populations of MDSCs, i.e., monocytic MDSCs (M-MDSC) and polymorphonuclear MDSCs (PMN-MDSC), which have different immunosuppressive properties. Inflammatory mediators are potent inducers and activators of MDSCs [110]. Treg cells are the immunosuppressive subset of $\mathrm{T}$ cells which can be maturated in thymus or in peripheral lymphoid organs and also in inflamed tissues $[113,114]$. Tregs are crucial regulators of innate and adaptive immunity, e.g., in self-tolerance. Tregs also has an important role in the maintenance of tissue homeostasis, e.g., in chronic inflammation [114].

Recent studies have revealed that ER stress has a significant role in the generation of immunosuppression in the tumor microenvironment $[7,8]$. Interestingly, there is clear evidence that the ER stress present in cancer cells can be transmitted into the recruited myeloid cells in the tumor microenvironment $[9,115]$. Mahadevan et al. [115] demonstrated that the UPR and the increased secretion capacity of inflammatory factors by tumor cells could be transmitted via a conditioned medium into bone marrow-derived dendritic cells (DC). These imprinted DCs expressed the markers of ER stress and secreted several pro-inflammatory cytokines, and moreover, they displayed an impaired antigen presentation and cross-priming of $\mathrm{CD} 8^{+} \mathrm{T}$ cells. The injection of these imprinted DCs into mice enhanced tumor growth. Several studies have revealed that it is not only tumor cells which can transmit ER stress into myeloid cells. For instance, Zhang et al. [10] demonstrated that the ER stress present in infected cardiomyocytes was able to transmit both the ER stress and pro-inflammatory properties into macrophages via soluble molecules but cell-cell contacts were not involved. In addition, ER stress can be transmitted between astrocytes, 
neurons, and microglia through soluble molecules in culture conditions [116]. It is known that ROS compounds and inflammatory mediators, e.g., IL- $1 \beta, \mathrm{TNF}-\alpha$, and HMGB1, are able to induce ER stress in several nonimmune cells [117-119]. It seems that there is a positive feedback loop between ER stress and inflammation. Inflammatory mediators can maintain and augment ER stress in inflamed tissues. Santos and Ferreira [120] speculated that this kind of loop might aggravate AD pathology. Currently, the molecular mechanisms of ER stress transmission remain to be clarified although inflammatory mediators and exosomes (see below) might have a crucial role in transmission. For instance, Hosoi et al. [121] revealed that the ER stress-induced exosomes contained both spliced and unspliced XBP1 mRNAs. In conclusion, it seems that if there is ER stress in host tissues, this induces the secretion of pro-inflammatory factors and exosomes which not only recruit myeloid cells into inflamed tissues but are also able to potentiate the immunosuppressive properties of infiltrated myeloid and lymphoid cells (Fig. 2).

Acute and chronic inflammatory insults are associated with compensatory anti-inflammatory responses. Many detrimental conditions, e.g., traumatic injuries and pathogen-induced sepsis, induce a systemic inflammatory response syndrome (SIRS) which concurrently provokes a compensatory antiinflammatory response syndrome (CARS) [122, 123]. The CARS state is linked with the activation of immunosuppressive cells, e.g., MDSCs, Tregs, and Mregs, which secrete antiinflammatory cytokines, such as TGF- $\beta$, and IL-10 [124, 125]. The immunosuppression present in the SIRS/CARS states, e.g., in sepsis and many autoimmune diseases, can increase the risk for persistent infections and multiple organ failure. However, not only severe insults but all chronic inflammatory disorders can provoke an immunosuppressive condition which counteracts the pro-inflammatory responses, thus alleviating the destructive effects of persistent inflammation $[4,111,126]$. Many pathological conditions involving chronic inflammation display both pro-inflammatory and anti-inflammatory characteristics, i.e., they create a local SIRS/CARS state. For instance, an increased level of immunosuppressive cells has been observed in obesity-driven inflammation [127], psoriasis [128], and neuroimmune diseases [129]. These states also involve an ER stress although the dynamics between immune cells and host tissue still needs to be clarified.

\section{ER stress augments the immunosuppressive phenotype of immune cells}

Infiltrated myeloid and lymphoid cells possess impressive plasticity which means that the microenvironment has an important role in the control of immune responses in tissues. The role of microenvironment in the activation of immunosuppressive network has been intensely studied in tumor biology. Tissue macrophages possess a remarkable functional plasticity in their capacity to adapt to alterations in tissue microenvironment $[130,131]$. Moreover, circulating monocytes recruited into inflamed tissues can be differentiated into macrophages. Macrophages can be polarized between the pro-inflammatory M1 phenotype and the anti-inflammatory M2 state. However, there exists a continuum of properties rather than a dichotomy between M1 and M2 phenotypes. Additionally, the M2 phenotype includes M2a, M2b, M2c, and M2d subtypes which have specific functional properties [130]. Commonly, the M1 macrophages are activated in acute inflammatory conditions, whereas M2 subtypes are involved in the resolution of inflammation as well as tissue repair [131]. The number of immunosuppressive macrophages, especially regulatory M2c subtype, increases in delayed inflammatory conditions and they secrete anti-inflammatory cytokines, e.g., IL-10 and TGF- $\beta$. Many other immune cells, i.e., $\mathrm{T}$ and $\mathrm{B}$ cells as well as dendritic, natural killer, and natural killer T cells, also involve regulatory, immunosuppressive phenotypes [132]. It is known that inflammatory mediators, e.g., those secreted by the ER-stressed nonimmune cells, are the major inducers of immunosuppressive phenotypes in infiltrated myeloid cells [111, 112, 133]. For instance, MDSCs can be activated by the exposure to several cytokines, e.g., IL-1 $\beta$, IL-6, IL-18, MIF and TNF- $\alpha$, complements $\mathrm{C} 3$ and $\mathrm{C} 52$, as well as many alarmins, such as HMGB1, HSP70, PGE2, and S100A8/a9. Moreover, ER stress stimulates the release of extracellular vesicles and exosomes which contain, e.g., danger-associated molecular patterns (DAMP) and noncoding RNAs [134, 135]. Exosomes augment the expansion of MDSCs and Tregs and thus they are crucial enhancers of immune suppression in tumors [136]. In addition, tumorderived exosomes can suppress the functions of effector immune cells, e.g. dendritic and NK cells. It seems that noncoding miRNAs are essential in the generation of immune suppression in tumors $[135,136]$. Interestingly, exosomes might have an important role in Alzheimer's pathology [137]. In the aging process, especially senescent cells possess an increased ability to secrete extracellular vesicles as a part of the SASP [138]. Given that exosomes contain a diverse set of molecules, it is still unknown how exosomes might promote tissue immunosuppression.

In the immune cells, ER stress contributes to many physiological functions, e.g., the development and differentiation of cells, although in a context-dependent manner, ER stress can activate immune responses [16]. Briefly, the intensity and prolongation of ER stress in infiltrated myeloid and lymphoid cells influence the immune responses, i.e., a severe ER stress promotes the immunogenic cell death (ICD), whereas chronic low-grade inflammation reinforces the tolerogenic and immunosuppressive properties of immune cells [8, 139]. Chronic inflammation stimulates the expansion of MDSCs, which are immature myeloid cells possessing a large set of immunosuppressive properties [112]. There are several studies indicating 
that ER stress in tumor cells increases the accumulation of MDSCs into tumor sites and enhances their immunosuppressive properties [11, 140]. Interestingly, Thevenot et al. [11] revealed that the expression of CHOP in MDSCs played a crucial role in the accumulation of these cells into mouse tumors and consequently CHOP was involved in the induction of their immunosuppressive activity. The expression of CHOP in MDSCs was mediated by ATF4 indicating that the PERK signaling pathway was activated. It is known that NFE2L2/ NRF2 transcription factor is a direct substrate of PERK which stimulates the NFE2L2-induced cell survival mechanisms, e.g., antioxidant protection [35]. Beury et al. [141] demonstrated that NFE2L2 regulated the survival and function of mouse MDSCs, especially guarding MDSCs against oxidative stress in inflammatory microenvironments. Thevenot et al. [11] demonstrated that the activation of CHOP in MDSCs induced the stimulation of IL-6/STAT3 signaling and the expression of ARG1. It seems that the induction of CHOP in MDSCs is not linked to apoptosis but instead to the increase in immunosuppressive activity and the survival of MDSCs in inflamed tissues.

It is known that ER stress affects the polarization of immune cells, thus affecting their inflammatory properties. Franco et al. [142] revealed that the treatment of human Treg clones with thapsigargin, an ER stress activator, induced a strong increase in the expression of CHOP and IL-10. The induction of anti-inflammatory IL-10 was suppressed by salubrinal, an eIF $2 \alpha$-mediated inhibitor of ER stress, indicating that the PERK-eIF2 $\alpha$ signaling is involved in the increase of immunosuppressive activity of Tregs. In contrast, Xu et al. [143] observed that the activation of the IRE1 $\alpha$-TRAF2 pathway through the deletion of Hrd1 protein impaired the expression of FOXP3 and also the immunosuppressive activity of mouse Tregs. Currently, the role of ER stress in the modulation of Treg activity is poorly understood. There is convincing evidence that ER stress can control the polarization of macrophages. Oh et al. [144] demonstrated that ER stress in human macrophages, induced by the exposure to either cholesterol or thapsigargin, promoted the shift from the pro-inflammatory M1 phenotype into the anti-inflammatory M2 subset. They also observed that the IRE $1 \alpha-\mathrm{CHOP}$ pathway was critical for M2 polarization and the subsequent increase in cholesterol uptake and the formation of foam cells. Furthermore, Suzuki et al. [54] reported that the macrophages isolated from the adipose tissue of CHOP knockout mice exhibit a significant increase in the level of the M2 subtype. It seems that the polarization of macrophages might be controlled in tissue specific manner as a response to the distinct pathology of host tissues. In this respect, it is interesting that in the inflammatory microenvironment of tumors, macrophages display the immunosuppressive M2-like phenotype, called the tumorassociated macrophages (TAM) [145]. Given the plasticity of macrophages and microglia, it is plausible that the specific macrophage/microglia subsets could appear in chronic inflammatory conditions, e.g., in aged tissues and Alzheimer's disease.

The main function of dendritic cells (DCs) is to process antigens and subsequently present them on their cell surface to $\mathrm{T}$ and $\mathrm{B}$ lymphocytes. It is recognized that the ER stress present in DCs impairs both the processing of antigens and their presentation [115, 146]. Interestingly, Cubillos-Ruiz et al. [6] reported that the XBP1 signaling was robustly activated in the DCs located in the human and mouse ovarian tumors. They revealed that the products of lipid peroxidation generated by tumor cells induced ER stress in DCs involving the strong activation of IRE1-XBP1 signaling. Cubillos-Ruiz et al. [6] also demonstrated that the activation of XBP1 disrupted homeostasis within DCs, i.e., it triggered abnormal lipid accumulation, inhibited antigen presentation, and reduced $T$ cell activation. These changes indicate that the stimulation of IRE1-XBP1 signaling switched the immunosuppressive phenotype of DCs and thus enhanced tumor progression. The ER stress-induced suppression of DCs has also been observed after a severe thermal injury in mice [147]. Zhu et al. [147] reported that a burn injury promoted the appearance of ER stress in splenic DCs which reduced the maturation of these cells and increased their apoptosis. The splenic DCs from injured mice also displayed a reduced capacity to enhance $\mathrm{T}$ cell proliferation and Th1 polarization. Treatment with salubrinal ameliorated the functional properties of splenic DCs after the thermal injury. It is known that this kind of injury provokes a systemic immunosuppressive response [148]. In conclusion, the ER stress present in inflamed host tissue enhances the recruitment of immune cells into tissues in attempts to terminate the inflammation but in chronic conditions, the pro-inflammatory phenotypes of immune cells will be switched into immunosuppressive subsets to prevent excessive tissue pathology.

\section{Activation of immunosuppressive network with aging and Alzheimer's disease}

The functional efficiency of human immune system declines with aging [149, 150]. The condition has been termed immunosenescence although it seems likely that immunosenescence is not the same phenomenon as the cellular senescence occurring in nonimmune cells. As long ago as the $1970 \mathrm{~s}$, the first studies appeared indicating that the defects in the immune system with aging were induced by an increased activity of immunosuppressive cells [151, 152]. There is some clinical evidence that the ageing process is associated with enhanced immunosuppression. For instance, (i) the risk for cancers is enhanced in elderly people, (ii) the efficiency of immunotherapy declines with aging, (iii) transplantation tolerance increases during the aging process, (iv) elderly people are vulnerable to infections, and (v) vaccination efficacy decreases 
during the aging process [153-155]. All these phenomena are associated with increased immunosuppression. Moreover, the survivors of cancer display a premature aging process [156] which may be caused by the tumor-induced systemic immunosuppression or treatments provided to combat the cancer which are known to provoke ER stress [157] and thus probably induce subsequent immunosuppression.

Currently, there is convincing evidence that the numbers of immunosuppressive MDSCs increases with aging in the blood of both humans [158, 159] and mice [160]. Several studies have also revealed an age-related increase in the accumulation of MDSCs into mouse bone marrow, spleen, and lymph nodes $[160,161]$. Considering the impressive plasticity and differentiation capacity of immature MDSCs, it may be difficult to calculate their actual abundance in peripheral tissues. However, Ruhland et al. [162] observed that the number of MDSCs was augmented in the skin of elderly people. Correspondingly, the numbers of Tregs expand with aging in the blood and lymphoid tissues in both humans and mice [163-165]. It seems that the survival of Tregs becomes improved with aging, thus enhancing the expansion of Treg population. An age-related increase in the numbers of Tregs has also been observed in mouse visceral adipose tissue [166] and human skin [167]. Aging affects also the polarization of macrophages in a tissue-specific manner. The immunosuppressive M2 phenotype increases with aging in the bone marrow, spleen, lungs, and skeletal muscles, whereas the proinflammatory M1 phenotype augments in the liver, heart muscle, and adipose tissues [168, 169]. Pathological changes accompanying aging might increase the level of the proinflammatory M1 phenotype, e.g., in heart and adipose tissues. There are also significant age-related alterations in the phenotypes of dendritic cells and NK cells $[170,171]$ although it needs to be clarified whether they represent immunosuppressive subtypes. Since the immunosuppressive network functions in a cooperative manner, it seems that the increased presence of MDSCs and Tregs with aging promotes the polarization of other members to adopt the immunosuppressive phenotypes. We have recently reviewed the phenotypes of immune cells including in the immunosuppressive network and changes in their phenotypes during the aging process [132].

Chronic inflammation and the simultaneous deposition of $\beta$-amyloid plaques indicate that immunosuppression could be associated with $\mathrm{AD}$ pathology. Currently, there are observations both for and against that proposal; these discrepancies might be attributable to the difficulties in examining immune cells which exhibit such significant plasticity in brain pathology. Several studies have indicated that the function of microglia is impaired in both transgenic $\mathrm{AD}$ mice and $\mathrm{AD}$ patients [172]. Microglial cells are unable to phagocytose $\beta$ amyloid aggregates provoking the deposition of neuritic plaques. It is also known that the overexpression of pro- inflammatory cytokines or the injection of LPS mitigates the deposition of $\beta$-amyloid in transgenic AD mice $[173,174]$. Moreover, the exposure of anti-inflammatory cytokines, e.g., TGF- $\beta 1$ and IL-10, enhances the deposition of $\beta$-amyloid in the brain of transgenic mice $[175,176]$. It seems that $\mathrm{AD}$ pathology is associated with increased immunosuppressive activity intended to protect neurons against detrimental inflammatory responses, but on the other hand, it prevents the cleansing of $\beta$-amyloid plaques.

Microglial cells are resident immune cells in the brain, but myeloid and lymphoid cells can infiltrate into the brain and affect the functions of microglial cells, especially in pathological conditions. Microglia, similarly to macrophages in other tissues, can be polarized between the pro-inflammatory M1 and anti-inflammatory M2 states [177]. Weekman et al. [178] demonstrated that the transition from the pro-inflammatory M1 state into the mixed phenotype, involving M2a and M2c markers, increased $\beta$-amyloid deposition in transgenic $\mathrm{AD}$ mice. In particular, the infiltrated immunosuppressive cells could trigger the M1/M2 shift of microglia through the secretion of anti-inflammatory cytokines, e.g., TGF- $\beta$ and IL-10. Mild ER stress induced the M1/M2b polarization of microglia and alleviated the LPS-induced inflammation in rat brain [179]. There are observations that the number of Treg cells becomes increased in the blood of the patients with mild cognitive impairment (MCI) and AD [180]. Moreover, Di Benedetto et al. [181] demonstrated that the number of FoxP3-positive cells, a key marker of Tregs, was significantly elevated in the hippocampus of post-mortem AD samples as compared with that of age-matched controls. A similar phenomenon was observed in the brains of transgenic $\mathrm{AD}$ mice. Recently, Thome et al. [182] reported that the frequency and immunosuppressive activity of MDSCs in blood markedly increased in the early phases of AD but were reduced in severe AD dementia. Interestingly, Baruch et al. [183] demonstrated that the transient depletion of FoxP3-positive cells increased the clearance of $\beta$-amyloid aggregates and alleviated inflammatory responses in transgenic $\mathrm{AD}$ mice. In conclusion, it seems that $\mathrm{AD}$ pathogenesis involves the activation of immunosuppressive network which suppresses the function of microglia and provokes the deposition of amyloid plagues. We have recently examined in detail the role of MDSCs in the pathogenesis of $\mathrm{AD}$ [184].

\section{Chronic immunosuppression disturbs the homeostasis of tissues}

Immunosuppressive cells possess cell-type-specific armament of inhibitory tools involving (i) the secretion of a diverse set of immunosuppressive cytokines, (ii) the expression of contactdependent checkpoint proteins, e.g., PD-1/PD-L1 and CTLA4 receptors, and (iii) the expression of amino acids catabolizing enzymes, such as arginase 1 (ARG1) and indoleamine 2,3- 
dioxygenase (IDO), which can inhibit protein synthesis and thus prevent the proliferation of immune cells $[112,185]$. The immunosuppressive network is cooperative since suppressive cells control the activity and polarization of other members in the network. Immunosuppressive cells have a fundamental role in the suppression of detrimental innate and adaptive immune responses and in the maintenance of immune self-tolerance. Overall, the activation of immunosuppressive cells, such as MDSCs and Tregs, has beneficial effects since it results in the resolution of acute inflammatory responses and the suppression of excessive inflammatory disorders, e.g., sepsis, autoimmune diseases, and transplantation $[110,112,186]$. However, in chronic inflammatory conditions, e.g. tumors, obesity, chronic infections, and neurodegenerative diseases, the impaired capacity of effector immune cells exerts detrimental effects on the maintenance of tissue homeostasis. The age-related immunosenescence evokes very similar changes in the phenotypes of immune cells as can be induced by the MDSC-driven immunosuppression [187]. Currently, it needs to be clarified whether the immunosenescent phenotype of immune cells is generated by the activation of the immunosuppressive network. However, ER stress stimulates the secretion of the same chemokines which are known to recruit MDSCs into inflamed tissues and trigger immunosuppression [188].

Immunosuppressive cells secrete anti-inflammatory cytokines, e.g. TGF- $\beta$ and IL-10, as well as reactive oxygen species (ROS). These factors are not only immunomodulators but they are also able to induce bystander effects in the cells of the host tissue. TGF- $\beta$ receptors 1 and 2 (TGFBR1/2) are commonly expressed in human tissues (Human Protein Atlas). TGF- $\beta$ cytokines trigger complex signaling pathways, mainly mediated via SMAD factors, which control several homeostatic functions, e.g. cell proliferation, differentiation, and senescence [189]. Fibrosis is probably the most common pathological change induced by TGF- $\beta$ signaling in several tissues [190]. Interestingly, ER stress is involved in the pathogenesis of many fibrotic diseases [191]. In particular, the myocardium and lungs are affected by fibrosis associated with aging. In some tissues, the ER stress-induced fibrosis also involves the appearance of myofibroblasts, i.e., the cells which secrete excessive amounts of extracellular matrix components, producing atheromatous plaques in blood vessels. TGF- $\beta$ is a potent inducer of the differentiation of fibroblasts into myofibroblasts [192]. It has been known for a long time that TGF- $\beta$ stimulates the expression of collagen and fibronectin by fibroblasts and thus it remodels the extracellular matrix [193]. In mouse skeletal muscles, TGF- $\beta$ provoked the appearance of endomysial fibrosis, collagen accumulation, and myofiber atrophy [194], common characteristics of sarcopenia.

In addition to fibrosis, TGF- $\beta$ signaling is a potent inducer of cellular senescence [195]. The responses might be both cell type-specific and context dependent. Senturk et al. [196] reported that the administration of TGF- $\beta$ induced the p15Ink $4 \mathrm{~b}$ and ROS-dependent senescent arrest in hepatocellular carcinoma cells and also inhibited tumor growth in mouse model. This effect is not only present in tumor cells since TGF- $\beta$ exposure can also trigger cellular senescence in human diploid fibroblasts and mouse keratinocytes [197, 198]. Frippiat et al. [197] demonstrated that the $\mathrm{H}_{2} \mathrm{O}_{2}$-induced oxidative stress stimulated the expression and secretion of TGF- $\beta 1$ in human fibroblasts. The $\mathrm{H}_{2} \mathrm{O}_{2}$-induced cellular senescence was inhibited in a TGFBR2-dependent manner. It is known that ROS compounds are important mediators of the MDSCinduced immunosuppression [199]. Several studies have revealed that the activation of MDSCs induced a robust increase in the secretion of ROS compounds through the activation of NADPH oxidase (NOX2) [199]. Interestingly, MDSCs themselves are resistant to oxidative stress since they have a significant level of NFE2L2-induced antioxidants [141]. It seems that immunosuppressive cells not only can arrest the proliferation of immune cells but TGF- $\beta$ and other immune modulators can also induce harmful bystander effects in host tissues.

Amino acid catabolism is an important mechanism in the control of immunosuppression [200, 201]. Given that many immune cells are auxotroph for certain amino acids, especially arginine and tryptophan, this means that the expression of the catabolic enzymes of these amino acids, i.e., ARG1 and IDO, by immunosuppressive cells restricts the function of auxotrophic immune cells in inflamed tissues. The amino acid shortage induced by immunosuppressive cells inhibits the function of many immune cells, e.g., T lymphocytes, but at the same time, it affects the cells of the host tissue although many neighboring cells are able to synthesize arginine but not tryptophan for their own purposes. This amino acid deficiency stimulates the GCN2 kinase which subsequently restricts protein translation via the phosphorylation of eIF-2 $\alpha$ [202]. In addition, the activation of ARG1 and IDO generates active metabolites which can affect the functions of inflamed host tissues. For instance, arginine is a shared substrate for ARG1 and nitric oxide synthase (NOS) and thus the increase in ARG1 activity reduces the generation of NO by NOS [203]. The activation of ARG1 also produces urea and augments polyamine synthesis. It has been observed that the ARG1 activation could promote the shift of macrophages to adopt an anti-inflammatory M2 phenotype, whereas the activation of NOS stimulated the proinflammatory M1 functions [203]. The tryptophan catabolism by the IDO of immune suppressive cells stimulates the kynurenine pathway and the production of many active metabolites, e.g., quinolinic and kynurenic acids, which are involved in the pathogenesis of several diseases including many neurodegenerative diseases [204]. There are disturbances in arginine metabolism in the aging process and age-related diseases [205] as well as in Alzheimer's disease [206]. Correspondingly, it seems that the kynurenine pathway has 
an essential role in many age-related diseases [207] and Alzheimer's disease [208]. In conclusion, the ER stressinduced inflammation, both during the aging process and many accompanying chronic diseases, generates an immunosuppressive state which not only prevents excessive inflammation but also insidiously degenerate host tissues as a consequence of the function of immune suppressive armament.

\section{Conclusions}

ER stress induces hormetic responses which are subject to the intensity of stress, i.e., mild ER stress augments stress tolerance, whereas excessive stress can trigger apoptosis or evoke necrotic injuries. ER stress is able to generate alarming factors which alert the immune system for the probable cell injuries. The immune response involves the activation of the tissueresident immune cells and the recruitment of myeloid and lymphoid cells into affected tissues. This means that the ER stress of the nonimmune cells can alert the immune system which subsequently will launch an acute inflammatory response in tissues. However, inflammatory responses, especially in chronic conditions, trigger a compensatory immunosuppression in an attempt to prevent more severe tissue damage. There is convincing evidence that the ER stress of host tissues can trigger ER stress in immune cells which affects the properties of immune cells, shifting them toward the antiinflammatory phenotype. This promotes the resolution of inflammation in acute states. In chronic conditions, where the insult cannot be removed, e.g., in the aging process or Alzheimer's disease, this state of immunosuppression has a crucial role in the prevention of detrimental inflammatory injuries. However, a persistent ER stress can trigger cellular senescence in inflammaging tissues or aggravate pathological processes underlying Alzheimer's disease. On the other hand, the mediators of immunosuppression secreted by immune suppressive cells, e.g., TGF- $\beta$, IL-10, and ROS, induce degenerative bystander effects in the affected tissues. This scenario indicates that ER stress has a crucial role in the control of the balance between inflammatory and immunosuppressive responses. This has been speculated to be present in many pathological processes but it also seems to occur in the inflammaging process and in Alzheimer's disease.

Acknowledgments Open access funding provided by University of Eastern Finland (UEF) including Kuopio University Hospital. The authors thank Dr. Ewen MacDonald for checking the language of the manuscript.

Funding information This study was financially supported by the grants from the Academy of Finland (AK297267, AK328443, and KK296840), the Kuopio University Hospital VTR grant (KK5503743), the Emil Aaltonen Foundation, the Sigrid Juselius Foundation, the Päivikki and
Sakari Sohlberg Foundation, the Finnish Cultural Foundation, and the Finnish Eye Foundation.

\section{Compliance with ethical standards}

Conflict of interest The authors state that there are no personal or institutional conflicts of interest.

Open Access This article is licensed under a Creative Commons Attribution 4.0 International License, which permits use, sharing, adaptation, distribution and reproduction in any medium or format, as long as you give appropriate credit to the original author(s) and the source, provide a link to the Creative Commons licence, and indicate if changes were made. The images or other third party material in this article are included in the article's Creative Commons licence, unless indicated otherwise in a credit line to the material. If material is not included in the article's Creative Commons licence and your intended use is not permitted by statutory regulation or exceeds the permitted use, you will need to obtain permission directly from the copyright holder. To view a copy of this licence, visit http://creativecommons.org/licenses/by/4.0/.

\section{References}

1. Ron D, Walter P (2007) Signal integration in the endoplasmic reticulum unfolded protein response. Nat Rev Mol Cell Biol 8: 519-529

2. Wang S, Kaufman RJ (2012) The impact of the unfolded protein response on human disease. J Cell Biol 197:857-867

3. Xiang C, Wang Y, Zhang H, Han F (2017) The role of endoplasmic reticulum stress in neurodegenerative disease. Apoptosis 22: $1-26$

4. Amodio G, Cichy J, Conde P, Matteoli G, Moreau A, Ochando J, Oral BH, Pekarova M, Ryan EJ, Roth J, Sohrabi Y, Cuturi MC, Gregori S (2019) Role of myeloid regulatory cells (MRCs) in maintaining tissue homeostasis and promoting tolerance in autoimmunity, inflammatory disease and transplantation. Cancer Immunol Immunother 68:661-672

5. Umansky V, Adema GJ, Baran J, Brandau S, Van Ginderachter JA, Hu X, Jablonska J, Mojsilovic S, Papadaki HA, Pico de Coana Y, Santegoets KCM, Santibanez JF, Serre K, Si Y, Sieminska I, Velegraki M, Fridlender ZG (2019) Interactions among myeloid regulatory cells in cancer. Cancer Immunol Immunother 68:645660

6. Cubillos-Ruiz JR, Silberman PC, Rutkowski MR, Chopra S, Perales-Puchalt A, Song M, Zhang S, Bettigole SE, Gupta D, Holcomb K, Ellenson LH, Caputo T, Lee AH, Conejo-Garcia JR, Glimcher LH (2015) ER stress sensor XBP1 controls antitumor immunity by disrupting dendritic cell homeostasis. Cell 161:1527-1538

7. Cubillos-Ruiz JR, Bettigole SE, Glimcher LH (2017) Tumorigenic and immunosuppressive effects of endoplasmic reticulum stress in cancer. Cell 168:692-706

8. Cubillos-Ruiz JR, Mohamed E, Rodriguez PC (2017) Unfolding anti-tumor immunity: ER stress responses sculpt tolerogenic myeloid cells in cancer. J Immunother Cancer 5:5

9. Mahadevan NR, Rodvold J, Sepulveda H, Rossi S, Drew AF, Zanetti M (2011) Transmission of endoplasmic reticulum stress and pro-inflammation from tumor cells to myeloid cells. Proc Natl Acad Sci U S A 108:6561-6566

10. Zhang H, Yue Y, Sun T, Wu X, Xiong S (2017) Transmissible endoplasmic reticulum stress from myocardiocytes to 
macrophages is pivotal for the pathogenesis of CVB3-induced viral myocarditis. Sci Rep 7:42162

11. Thevenot PT, Sierra RA, Raber PL, Al-Khami AA, Trillo-Tinoco J, Zarreii P, Ochoa AC, Cui Y, Del Valle L, Rodriguez PC (2014) The stress-response sensor chop regulates the function and accumulation of myeloid-derived suppressor cells in tumors. Immunity 41:389-401

12. Pluquet O, Pourtier A, Abbadie C (2015) The unfolded protein response and cellular senescence. A review in the theme: cellular mechanisms of endoplasmic reticulum stress signaling in health and disease. Am J Phys Cell Phys 308:C415-C425

13. Druelle C, Drullion C, Desle J, Martin N, Saas L, Cormenier J, Malaquin N, Huot L, Slomianny C, Bouali F, Vercamer C, Hot D, Pourtier A, Chevet E, Abbadie C, Pluquet O (2016) ATF6 $\alpha$ regulates morphological changes associated with senescence in human fibroblasts. Oncotarget 7:67699-67715

14. Cormenier J, Martin N, Desle J, Salazar-Cardozo C, Pourtier A, Abbadie C, Pluquet O (2018) The ATF6 $\alpha$ arm of the unfolded protein response mediates replicative senescence in human fibroblasts through a COX2/prostaglandin E2 intracrine pathway. Mech Ageing Dev 170:82-91

15. Hoozemans JJ, van Haastert ES, Nijholt DA, Rozemuller AJ, Eikelenboom P, Scheper W (2009) The unfolded protein response is activated in pretangle neurons in Alzheimer's disease hippocampus. Am J Pathol 174:1241-1251

16. Grootjans J, Kaser A, Kaufman RJ, Blumberg RS (2016) The unfolded protein response in immunity and inflammation. Nat Rev Immunol 16:469-484

17. Ruggiano A, Foresti O, Carvalho P (2014) Quality control: ERassociated degradation: protein quality control and beyond. J Cell Biol 204:869-879

18. Senft D, Ronai ZA (2015) UPR, autophagy, and mitochondria crosstalk underlies the ER stress response. Trends Biochem Sci 40:141-148

19. Song S, Tan J, Miao Y, Zhang Q (2018) Crosstalk of ER stressmediated autophagy and ER-phagy: Involvement of UPR and the core autophagy machinery. J Cell Physiol 233:3867-3874

20. Yorimitsu T, Nair U, Yang Z, Klionsky DJ (2006) Endoplasmic reticulum stress triggers autophagy. J Biol Chem 281:3029930304

21. Khaminets A, Heinrich T, Mari M, Grumati P, Huebner AK, Akutsu M, Liebmann L, Stolz A, Nietzsche S, Koch N, Mauthe M, Katona I, Qualmann B, Weis J, Reggiori F, Kurth I, Hübner CA, Dikic I (2015) Regulation of endoplasmic reticulum turnover by selective autophagy. Nature 522:354-358

22. Ghosh AK, Mau T, O'Brien M, Garg S, Yung R (2016) Impaired autophagy activity is linked to elevated ER-stress and inflammation in aging adipose tissue. Aging (Albany NY) 8:2525-2537

23. van Vliet AR, Agostinis P (2018) Mitochondria-associated membranes and ER stress. Curr Top Microbiol Immunol 414:73-102

24. Moltedo O, Remondelli P, Amodio G (2019) The mitochondriaendoplasmic reticulum contacts and their critical role in aging and age-associated diseases. Front Cell Dev Biol 7:172

25. Volgyi K, Juhasz G, Kovacs Z, Penke B (2015) Dysfunction of endoplasmic reticulum (ER) and mitochondria (MT) in Alzheimer's disease: The role of the ER-MT cross-talk. Curr Alzheimer Res 12:655-672

26. Adams CJ, Kopp MC, Larburu N, Nowak PR, Ali MMU (2019) Structure and molecular mechanism of ER stress signaling by the unfolded protein response signal activator IRE1. Front Mol Biosci 6:11

27. Maurel M, Chevet E, Tavernier J, Gerlo S (2014) Getting RIDD of RNA: IRE1 in cell fate regulation. Trends Biochem Sci 39:245254
28. Wu R, Zhang QH, Lu YJ, Ren K, Yi GH (2015) Involvement of the IRE1 $\alpha$-XBP1 pathway and XBP1s-dependent transcriptional reprogramming in metabolic diseases. DNA Cell Biol 34:6-18

29. Martinez G, Vidal RL, Mardones P, Serrano FG, Ardiles AO, Wirth C, Valdes P, Thielen P, Schneider BL, Kerr B, Valdes JL, Palacios AG, Inestrosa NC, Glimcher LH, Hetz C (2016) Regulation of memory formation by the transcription factor XBP1. Cell Rep 14:1382-1394

30. Abdullah A, Ravanan P (2018) The unknown face of IRE1 $\alpha$ Beyond ER stress. Eur J Cell Biol 97:359-368

31. McQuiston A, Diehl JA (2017) Recent insights into PERKdependent signaling from the stressed endoplasmic reticulum. F1000Res 6:1897

32. B'chir W, Maurin AC, Carraro V, Averous J, Jousse C, Muranishi Y, Parry L, Stepien G, Fafournoux P, Bruhat A (2013) The eIF2 $\alpha$ / ATF4 pathway is essential for stress-induced autophagy gene expression. Nucleic Acids Res 41:7683-7699

33. Jiang HY, Wek SA, McGrath BC, Scheuner D, Kaufman RJ, Cavener DR, Wek RC (2003) Phosphorylation of the $\alpha$ subunit of eukaryotic initiation factor 2 is required for activation of NF- $\mathrm{KB}$ in response to diverse cellular stresses. Mol Cell Biol 23:56515663

34. Ohno M (2018) PERK as a hub of multiple pathogenic pathways leading to memory deficits and neurodegeneration in Alzheimer's disease. Brain Res Bull 141:72-78

35. Cullinan SB, Zhang D, Hannink M, Arvisais E, Kaufman RJ, Diehl JA (2003) Nrf2 is a direct PERK substrate and effector of PERK-dependent cell survival. Mol Cell Biol 23:7198-7209

36. Bailey D, O'Hare P (2007) Transmembrane bZIP transcription factors in ER stress signaling and the unfolded protein response. Antioxid Redox Signal 9:2305-2321

37. Hillary RF, FitzGerald U (2018) A lifetime of stress: ATF6 in development and homeostasis. J Biomed Sci 25:48

38. Teske BF, Wek SA, Bunpo P, Cundiff JK, McClintick JN, Anthony TG, Wek RC (2011) The eIF2 kinase PERK and the integrated stress response facilitate activation of ATF6 during endoplasmic reticulum stress. Mol Biol Cell 22:4390-4405

39. Yoshida H, Matsui T, Yamamoto A, Okada T, Mori K (2001) XBP1 mRNA is induced by ATF6 and spliced by IRE1 in response to ER stress to produce a highly active transcription factor. Cell 107:881-891

40. Lopez-Otin C, Blasco MA, Partridge L, Serrano M, Kroemer G (2013) The hallmarks of aging. Cell 153:1194-1217

41. Estebanez B, de Paz JA, Cuevas MJ, Gonzalez-Gallego J (2018) Endoplasmic reticulum unfolded protein response, aging and exercise: an update. Front Physiol 9:1744

42. Tavernarakis N (2008) Ageing and the regulation of protein synthesis: a balancing act? Trends Cell Biol 18:228-235

43. Pakos-Zebrucka K, Koryga I, Mnich K, Ljujic M, Samali A, Gorman AM (2016) The integrated stress response. EMBO Rep 17:1374-1395

44. Salminen A, Kaarniranta K (2010) ER stress and hormetic regulation of the aging process. Ageing Res Rev 9:211-217

45. Matai L, Sarkar GC, Chamoli M, Malik Y, Kumar SS, Rautela U, Jana NR, Chakraborty K, Mukhopadhyay A (2019) Dietary restriction improves proteostasis and increases life span through endoplasmic reticulum hormesis. Proc Natl Acad Sci U S A 116: 17383-17392

46. Li J, Wang JJ, Zhang SX (2011) Preconditioning with endoplasmic reticulum stress mitigates retinal endothelial inflammation via activation of X-box binding protein 1. J Biol Chem 286:49124921

47. Leonard A, Paton AW, El-Quadi M, Paton JC, Fazal F (2014) Preconditioning with endoplasmic reticulum stress ameliorates endothelial cell inflammation. PLoS One 9:e110949 
48. Naidoo N, Ferber M, Master M, Zhu Y, Pack AI (2008) Aging impairs the unfolded protein response to sleep deprivation and leads to proapoptotic signaling. J Neurosci 28:6539-6548

49. Ghosh AK, Garg SK, Mau T, O'Brien M, Liu J, Yung R (2015) Elevated endoplasmic reticulum stress response contributes to adipose tissue inflammation in aging. J Gerontol A Biol Sci Med Sci 70:1320-1329

50. Baehr LM, West DW, Marcotte G, Marshall AG, De Sousa LG, Baar K, Bodine SC (2016) Age-related deficits in skeletal muscle recovery following disuse are associated with neuromuscular junction instability and ER stress, not impaired protein synthesis. Aging (Albany NY) 8:127-146

51. Ikeyama S, Wang XT, Li J, Podlutsky A, Martindale JL, Kokkonen G, van Huizen R, Gorospe M, Holbrook NJ (2003) Expression of the pro-apoptotic gene gadd153/chop is elevated in liver with aging and sensitizes cells to oxidant injury. J Biol Chem 278:16726-16731

52. Lenox AR, Bhootada Y, Gorbatyuk O, Fullard R, Gorbatyuk M (2015) Unfolded protein response is activated in aged retinas. Neurosci Lett 609:30-35

53. Yang Y, Liu L, Naik I, Braunstein Z, Zhong J, Ren B (2017) Transcription factor C/EBP homologous protein in health and diseases. Front Immunol 8:1612

54. Suzuki T, Gao J, Ishigaki Y, Kondo K, Sawada S, Izumi T, Uno K, Kaneko K, Tsukita S, Takahashi K, Asao A, Ishii N, Imai J, Yamada T, Oyadomari S, Katagiri H (2017) ER stress protein CHOP mediates insulin resistance by modulating adipose tissue macrophage polarity. Cell Rep 18:2045-2057

55. Willy JA, Young SK, Stevens JL, Masuoka HC, Wek RC (2015) CHOP links endoplasmic reticulum stress to NF- $\mathrm{KB}$ activation in the pathogenesis of nonalcoholic steatohepatitis. Mol Biol Cell 26: 2190-2204

56. van Deursen JM (2014) The role of senescent cells in ageing. Nature 509:439-446

57. Freund A, Orjalo AV, Desprez PY, Campisi J (2010) Inflammatory networks during cellular senescence: causes and consequences. Trends Mol Med 16:238-246

58. Salminen A, Kauppinen A, Kaarniranta K (2012) Emerging role of NF- $\mathrm{KB}$ signaling in the induction of senescence-associated secretory phenotype (SASP). Cell Signal 24:835-845

59. Oubaha M, Miloudi K, Dejda A, Guber V, Mawambo G, Germain MA, Bourdel G, Popovic N, Rezende FA, Kaufman RJ, Mallette FA, Sapieha P (2016) Senescence-associated secretory phenotype contributes to pathological angiogenesis in retinopathy. Sci Transl Med 8:362ra144

60. Childs BG, Gluscevic M, Baker DJ, Laberge RM, Marquess D, Dananberg J, van Deursen JM (2017) Senescent cells: an emerging target for diseases of ageing. Nat Rev Drug Discov 16:718735

61. Gerakis Y, Hetz C (2018) Emerging roles of ER stress in the etiology and pathogenesis of Alzheimer's disease. FEBS J 285: 995-1011

62. Hoozemans JJ, Veerhuis R, Van Haastert ES, Rozemuller JM, Baas F, Eikelenboom P, Scheper W (2005) The unfolded protein response is activated in Alzheimer's disease. Acta Neuropathol 110:165-172

63. Abisambra JF, Jinwal UK, Blair LJ, O'Leary JC 3rd, Li Q, Brady S, Wang L, Guidi CE, Zhang B, Nordhues BA, Cockman M, Suntharalingham A, Li P, Jin Y, Atkins CA, Dickey CA (2013) Tau accumulation activates the unfolded protein response by impairing endoplasmic reticulum-associated degradation. J Neurosci 33:9498-9507

64. Meier S, Bell M, Lyons DN, Ingram A, Chen J, Gensel JC, Zhu H, Nelson PT, Abisambra JF (2015) Identification of novel Tau interactions with endoplasmic reticulum proteins in Alzheimer's disease brain. J Alzheimers Dis 48:687-702
65. Nijholt DA, van Haastert ES, Rozemuller AJ, Scheper W, Hoozemans JJ (2012) The unfolded protein response is associated with early tau pathology in the hippocampus of tauopathies. $\mathrm{J}$ Pathol 226:693-702

66. Fouillet A, Levet C, Virgone A, Robin M, Dourlen P, Rieusset J, Belaidi E, Ovize M, Touret M, Nataf S, Mollereau B (2012) ER stress inhibits neuronal death by promoting autophagy. Autophagy 8:915-926

67. Fonseca AC, Ferreiro E, Oliveira CR, Cardoso SM, Pereira CF (2013) Activation of the endoplasmic reticulum stress response by the amyloid- $\beta$ 1-40 peptide in brain endothelial cells. Biochim Biophys Acta 1832:2191-2203

68. Marwarha G, Rostad S, Lilek J, Kleinjan M, Schommer J, Ghribi O (2017) Palmitate increases $\beta$-site A $\beta$ PP-cleavage enzyme 1 activity and amyloid- $\beta$ genesis by evoking endoplasmic reticulum stress and subsequent $\mathrm{C} / \mathrm{EBP}$ homologous protein activation. J Alzheimers Dis 57:907-925

69. Zhu B, Jiang L, Huang T, Zhao Y, Liu T, Zhong Y, Li X, Campos A, Pomeroy K, Masliah E, Zhang D, Xu H (2017) ER-associated degradation regulates Alzheimer's amyloid pathology and memory function by modulating $\gamma$-secretase activity. Nat Commun 8: 1472

70. Duran-Aniotz C, Cornejo VH, Espinoza S, Ardiles AO, Medinas DB, Salazar C, Foley A, Gajardo I, Thielen P, Iwawaki T, Scheper W, Soto C, Palacios AG, Hoozemans JJM, Hetz C (2017) IRE1 signaling exacerbates Alzheimer's disease pathogenesis. Acta Neuropathol 134:489-506

71. Salminen A, Kauppinen A, Suuronen T, Kaarniranta K, Ojala J (2009) ER stress in Alzheimer's disease: a novel neuronal trigger for inflammation and Alzheimer's pathology. J Neuroinflammation 6:41

72. Chen X, Guo X, Ge Q, Zhao Y, Mu H, Zhang J (2019) ER stress activates the NLRP3 inflammasome: A novel mechanism of atherosclerosis. Oxidative Med Cell Longev 2019:3462530

73. Zhang J, Zhang K, Li Z, Guo B (2016) ER stress-induced inflammasome activation contributes to hepatic inflammation and steatosis. J Clin Cell Immunol 7:457

74. Kheitan S, Minuchehr Z, Soheili ZS (2017) Exploring the cross talk between ER stress and inflammation in age-related macular degeneration. PLoS One 12:0181667

75. Smith JA (2018) Regulation of cytokine production by the unfolded protein response; implications for infection and autoimmunity. Front Immunol 9:422

76. Kolattukudy PE, Niu J (2012) Inflammation, endoplasmic reticulum stress, autophagy, and the monocyte chemoattractant protein1/CCR2 pathway. Circ Res 110:174-189

77. Gargalovic PS, Gharavi NM, Clark MJ, Pagnon J, Yang WP, He A, Truong A, Baruch-Oren T, Berliner JA, Kirchgessner TG, Lusis AJ (2006) The unfolded protein response is an important regulator of inflammatory genes in endothelial cells. Arterioscler Thromb Vasc Biol 26:2490-2496

78. Ying R, Li SW, Chen JY, Zhang HF, Yang Y, Gu ZJ, Chen YX, Wang JF (2018) Endoplasmic reticulum stress in perivascular adipose tissue promotes destabilization of atherosclerotic plaque by regulating GM-CSF paracrine. J Transl Med 16:105

79. Kim HM, Lee ES, Lee BR, Yadav D, Kim YM, Ko HJ, Park KS, Lee EY, Chung CH (2015a) C-C chemokine receptor 2 inhibitor ameliorates hepatic steatosis by improving ER stress and inflammation in a type 2 diabetic mouse model. PLoS One 10:e0120711

80. Kapoor N, Niu J, Saad Y, Kumar S, Sirakova T, Becerra E, Li X, Kolattukudy PE (2015) Transcription factors STAT6 and KLF4 implement macrophage polarization via the dual catalytic powers of MCPIP. J Immunol 194:6011-6023

81. Zhang K, Kaufman RJ (2008) From endoplasmic-reticulum stress to the inflammatory response. Nature $454: 455-462$ 
82. Chaudhari N, Talwar P, Parimisetty A, Lefebvre d'Hellencourt C, Ravanan P (2014) A molecular web: endoplasmic reticulum stress, inflammation, and oxidative stress. Front Cell Neurosci 8: 213

83. Keestra-Gounder AM, Byndloss MX, Seyffert N, Young BM, Chavez-Arroyo A, Tsai AY, Cevallos SA, Winter MG, Pham $\mathrm{OH}$, Tiffany CR, de Jong MF, Kerrinnes T, Ravindran R, Luciw PA, McSorley SJ, Bäumler AJ, Tsolis RM (2016) NOD1 and NOD2 signalling links ER stress with inflammation. Nature 532: 394-397

84. Tesch GH, Ma FY, Nikolic-Paterson DJ (2016) ASK1: a new therapeutic target for kidney disease. Am J Physiol Ren Physiol 311:F373-F381

85. Kim S, Joe Y, Kim HJ, Kim YS, Jeong SO, Pae HO, Ryter SW, Surh YJ, Chung HT (2015) Endoplasmic reticulum stress-induced IRE $1 \alpha$ activation mediates cross-talk of GSK-3 $\beta$ and XBP-1 to regulate inflammatory cytokine production. J Immunol 194:44984506

86. Lerner AG, Upton JP, Praveen PV, Ghosh R, Nakagawa Y, Igbaria A, Shen S, Nguyen V, Backes BJ, Heiman M, Heintz N, Greengard P, Hui S, Tang Q, Trusina A, Oakes SA, Papa FR (2012) IRE1 $\alpha$ induces thioredoxin-interacting protein to activate the NLRP3 inflammasome and promote programmed cell death under irremediable ER stress. Cell Metab 16:250-264

87. Robblee MM, Kim CC, Porter Abate J, Valdearcos M, Sandlund KL, Shenoy MK, Volmer R, Iwawaki T, Koliwad SK (2016) Saturated fatty acids engage an IRE1 $\alpha$-dependent pathway to activate the NLRP3 inflammasome in myeloid cells. Cell Rep 14: 2611-2623

88. Place DE, Kanneganti TD (2018) Recent advances in inflammasome biology. Curr Opin Immunol 50:32-38

89. Oslowski CM, Hara T, O'Sullivan-Murphy B, Kanekura K, Lu S, Hara M, Ishigaki S, Zhu LJ, Hayashi E, Hui ST, Greiner D, Kaufman RJ, Bortell R, Urano F (2012) Thioredoxin-interacting protein mediates ER stress-induced $\beta$ cell death through initiation of the inflammasome. Cell Metab 16:265-273

90. Guthrie LN, Abiraman K, Plyler ES, Sprenkle NT, Gibson SA, McFarland BC, Rajbhandari R, Rowse AL, Benveniste EN, Meares GP (2016) Attenuation of PKR-like ER kinase (PERK) signaling selectively controls endoplasmic reticulum stressinduced inflammation without compromising immunological responses. J Biol Chem 291:15830-15840

91. Meares GP, Liu Y, Rajbhandari R, Qin H, Nozell SE, Mobley JA, Corbett JA, Benveniste EN (2014) PERK-dependent activation of JAK1 and STAT3 contributes to endoplasmic reticulum stressinduced inflammation. Mol Cell Biol 34:3911-3925

92. Lebeaupin C, Proics E, de Bieville CH, Rousseau D, Bonnafous S, Patouraux S, Adam G, Lavallard VJ, Rovere C, Le Thuc O, SaintPaul MC, Anty R, Schneck AS, Iannelli A, Gugenheim J, Tran A, Gual P, Bailly-Maitre B (2015) ER stress induces NLRP3 inflammasome activation and hepatocyte death. Cell Death Dis 6:e1879

93. Rozpedek W, Pytel D, Mucha B, Leszczynska H, Diehl JA, Majsterek I (2016) The role of the PERK/eIF2 $\alpha /$ ATF4/CHOP signaling pathway in tumor progression during endoplasmic reticulum stress. Curr Mol Med 16:533-544

94. Wek RC, Jiang HY, Anthony TG (2006) Coping with stress: eIF2 kinases and translational control. Biochem Soc Trans 34:7-11

95. Yamazaki H, Hiramatsu N, Hayakawa K, Tagawa Y, Okamura M, Ogata R, Huang T, Nakajima S, Yao J, Paton AW, Paton JC, Kitamura M (2009) Activation of the Akt-NF-kB pathway by subtilase cytotoxin through the ATF6 branch of the unfolded protein response. J Immunol 183:1480-1487

96. DeZwaan-McCabe D, Riordan JD, Arensdorf AM, Icardi MS, Dupuy AJ, Rutkowski DT (2013) The stress-regulated transcription factor $\mathrm{CHOP}$ promotes hepatic inflammatory gene expression, fibrosis, and oncogenesis. PLoS Genet 9:e1003937

97. Franceschi C, Bonafe M, Valensin S, Olivieri F, De Luca M, Ottaviani E, De Benedictis G (2000) Inflamm-aging. An evolutionary perspective on immunosenescence. Ann N Y Acad Sci 908:244-254

98. Salminen A, Huuskonen J, Ojala J, Kauppinen A, Kaarniranta K, Suuronen T (2008) Activation of innate immunity system during aging: NF- $\mathrm{KB}$ signaling is the molecular culprit of inflamm-aging. Ageing Res Rev 7:83-105

99. Chinn IK, Blackburn CC, Manley NR, Sempowski GD (2012) Changes in primary lymphoid organs with aging. Semin Immunol 24:309-320

100. Kovtonyuk LV, Fritsch K, Feng X, Manz MG, Takizawa H (2016) Inflamm-aging of hematopoiesis, hematopoietic stem cells, and the bone marrow microenvironment. Front Immunol 7:502

101. Benayoun BA, Pollina EA, Singh PP, Mahmoudi S, Harel I, Casey KM, Dulken BW, Kundaje A, Brunet A (2019) Remodeling of epigenome and transcriptome landscapes with aging in mice reveals widespread induction of inflammatory responses. Genome Res 29:697-709

102. Elias HK, Bryder D, Park CY (2017) Molecular mechanisms underlying lineage bias in aging hematopoiesis. Semin Hematol 54: 4-11

103. Heneka MT, Carson MJ, El Khoury J et al (2015) Neuroinflammation in Alzheimer's disease. Lancet Neurol 14: 388-405

104. Salminen A, Ojala J, Kauppinen A, Kaarniranta K, Suuronen T (2009) Inflammation in Alzheimer's disease: amyloid- $\beta$ oligomers trigger innate immunity defence via pattern recognition receptors. Prog Neurobiol 87:181-194

105. Miguel-Alvarez M, Santos-Lozano A, Sanchis-Gomar F, FiuzaLuces C, Pareja-Galeano H, Garatachea N, Lucia A (2015) Nonsteroidal anti-inflammatory drugs as a treatment for Alzheimer's disease: a systematic review and meta-analysis of treatment effect. Drugs Aging 32:139-147

106. Schilling S, Rahfeld JU, Lues I, Lemere CA (2018) Passive A $\beta$ immunotherapy: current achievements and future perspectives. Molecules 23:1068

107. Salminen A, Ojala J, Suuronen T, Kaarniranta K, Kauppinen A (2008) Amyloid- $\beta$ oligomers set fire to inflammasomes and induce Alzheimer's pathology. J Cell Mol Med 12:2255-2262

108. Heneka MT, Kummer MP, Stutz A, Delekate A, Schwartz S, Vieira-Saecker A, Griep A, Axt D, Remus A, Tzeng TC, Gelpi E, Halle A, Korte M, Latz E, Golenbock DT (2013) NLRP3 is activated in Alzheimer's disease and contributes to pathology in APP/PS1 mice. Nature 493:674-678

109. Itzhaki RF (2017) Herpes simplex virus type 1 and Alzheimer's disease: possible mechanisms and signposts. FASEB J 31:32163226

110. Ostrand-Rosenberg S, Sinha P (2009) Myeloid-derived suppressor cells: linking inflammation and cancer. J Immunol 182:4499-4506

111. Wang D, DuBois RN (2015) Immunosuppression associated with chronic inflammation in the tumor microenvironment. Carcinogenesis 36:1085-1093

112. Gabrilovich DI, Nagaraj S (2009) Myeloid-derived suppressor cells as regulators of the immune system. Nat Rev Immunol 9: $162-174$

113. Josefowicz SZ, Lu LF, Rudensky AY (2012) Regulatory T cells: mechanisms of differentiation and function. Annu Rev Immunol 30:531-564

114. Sharma A, Rudra D (2018) Emerging functions of regulatory $\mathrm{T}$ cells in tissue homeostasis. Front Immunol 9:883

115. Mahadevan NR, Anufreichik V, Rodvold JJ, Chiu KT, Sepulveda H, Zanetti M (2012) Cell-extrinsic effects of tumor ER stress 
imprint myeloid dendritic cells and impair $\mathrm{CD} 8^{+} \mathrm{T}$ cell priming. PLoS One 7:e51845

116. Sprenkle NT, Lahiri A, Simpkins JW, Meares GP (2019) Endoplasmic reticulum stress is transmissible in vitro between cells of the central nervous system. J Neurochem 148:516-530

117. Xue X, Piao JH, Nakajima A, Sakon-Komazawa S, Kojima Y, Mori K, Yagita H, Okumura K, Harding H, Nakano H (2005) Tumor necrosis factor $\alpha(\mathrm{TNF} \alpha)$ induces the unfolded protein response (UPR) in a reactive oxygen species (ROS)-dependent fashion, and the UPR counteracts ROS accumulation by TNF $\alpha$. J Biol Chem 280:33917-33925

118. Verma G, Datta M (2010) IL-1 $\beta$ induces ER stress in a JNK dependent manner that determines cell death in human pancreatic epithelial MIA PaCa-2 cells. Apoptosis 15:864-876

119. He Q, Fu Y, Ding X, Li D, Wang Z, Tian D, Yan W (2018) Highmobility group box 1 induces endoplasmic reticulum stress and activates hepatic stellate cells. Lab Investig 98:1200-1210

120. Santos LE, Ferreira ST (2018) Crosstalk between endoplasmic reticulum stress and brain inflammation in Alzheimer's disease. Neuropharmacology 136:350-360

121. Hosoi T, Nakashima M, Ozawa K (2018) Incorporation of the endoplasmic reticulum stress-induced spliced form of XBP1 mRNA in the exosomes. Front Physiol 9:1357

122. Adib-Conquy M, Cavaillon JM (2009) Compensatory antiinflammatory response syndrome. Thromb Haemost 101:36-47

123. Balk RA (2014) Systemic inflammatory response syndrome (SIRS): where did it come from and is it still relevant today? Virulence 5:20-26

124. Mira JC, Gentile LF, Mathias BJ, Efron PA, Brakenridge SC, Mohr AM, Moore FA, Moldawer LL (2017) Sepsis pathophysiology, chronic critical illness, and persistent inflammationimmunosuppression and catabolism syndrome. Crit Care Med 45:253-262

125. Venet F, Monneret G (2018) Advances in the understanding and treatment of sepsis-induced immunosuppression. Nat Rev Nephrol 14:121-137

126. Kanterman J, Sade-Feldman M, Baniyash M (2012) New insights into chronic inflammation-induced immunosuppression. Semin Cancer Biol 22:307-318

127. Okwan-Duodu D, Umpierrez GE, Brawley OW, Diaz R (2013) Obesity-driven inflammation and cancer risk: role of myeloid derived suppressor cells and alternately activated macrophages. Am J Cancer Res 3:21-33

128. Cao LY, Chung JS, Teshima T, Feigenbaum L, Cruz PD Jr, Jacobe HT, Chong BF, Ariizumi K (2016) Myeloid-derived suppressor cells in psoriasis are an expanded population exhibiting diverse Tcell-suppressor mechanisms. J Invest Dermatol 136:1801-1810

129. Melero-Jerez C, Ortega MC, Moline-Velazquez V, Clemente D (2016) Myeloid derived suppressor cells in inflammatory conditions of the central nervous system. Biochim Biophys Acta 1862: $368-380$

130. Roszer T (2015) Understanding the mysterious M2 macrophage through activation markers and effector mechanisms. Mediat Inflamm 2015:816460

131. Murray PJ (2017) Macrophage polarization. Annu Rev Physiol 79:541-566

132. Salminen A (2020) Activation of immunosuppressive network in the aging process. Ageing Res Rev. https://doi.org/10.1016/j.arr. 2019.100998

133. Ostrand-Rosenberg S, Fenselau C (2018) Myeloid-derived suppressor cells: Immune-suppressive cells that impair antitumor immunity and are sculpted by their environment. J Immunol 200: 422-431

134. Collett GP, Redman CW, Sargent IL, Vatish M (2018) Endoplasmic reticulum stress stimulates the release of extracellular vesicles carrying danger-associated molecular pattern (DAMP) molecules. Oncotarget 9:6707-6717

135. Graner MW, Schnell S, Olin MR (2018) Tumor-derived exosomes, microRNAs, and cancer immune suppression. Semin Immunopathol 40:505-515

136. Chen W, Jiang J, Xia W, Huang J (2017) Tumor-related exosomes contribute to tumor-promoting microenvironment: An immunological perspective. J Immunol Res 2017:1073947

137. Sardar Sinha M, Ansell-Schultz A, Civitelli L, Hildesjö C, Larsson M, Lannfelt L, Ingelsson M, Hallbeck M (2018) Alzheimer's disease pathology propagation by exosomes containing toxic amyloid- $\beta$ oligomers. Acta Neuropathol 136:41-56

138. Kadota T, Fujita Y, Yoshioka Y, Araya J, Kuwano K, Ochiya T (2018) Emerging role of extracellular vesicles as a senescenceassociated secretory phenotype: Insights into the pathophysiology of lung diseases. Mol Asp Med 60:92-103

139. Song M, Cubillos-Ruiz JR (2019) Endoplasmic reticulum stress responses in intratumoral immune cells: implications for cancer immunotherapy. Trends Immunol 40:128-141

140. Lee BR, Chang SY, Hong EH, Kwon BE, Kim HM, Kim YJ, Lee J, Cho HJ, Cheon JH, Ko HJ (2014) Elevated endoplasmic reticulum stress reinforced immunosuppression in the tumor microenvironment via myeloid-derived suppressor cells. Oncotarget 5: 12331-12345

141. Beury DW, Carter KA, Nelson C, Sinha P, Hanson E, Nyandjo M, Fitzgerald PJ, Majeed A, Wali N, Ostrand-Rosenberg S (2016) Myeloid-derived suppressor cell survival and function are regulated by the transcription factor Nrf2. J Immunol 196:3470-3478

142. Franco A, Almanza G, Burns JC, Wheeler M, Zanetti M (2010) Endoplasmic reticulum stress drives a regulatory phenotype in human T-cell clones. Cell Immunol 266:1-6

143. Xu Y, Melo-Cardenas J, Zhang Y, Gau I, Wei J, Montauti E, Zhang Y, Gao B, Jin H, Sun Z, Lee SM, Fang D (2019) The E3 ligase Hrd1 stabilizes Tregs by antagonizing inflammatory cytokineinduced ER stress response. JCI Insight 4:e121887

144. Oh J, Riek AE, Weng S, Petty M, Kim D, Colonna M, Cella M, Bernal-Mizrachi C (2012) Endoplasmic reticulum stress controls M2 macrophage differentiation and foam cell formation. J Biol Chem 287:11629-11641

145. Mantovani A, Marchesi F, Malesci A, Laghi L, Allavena P (2017) Tumour-associated macrophages as treatment targets in oncology. Nat Rev Clin Oncol 14:399-416

146. Granados DP, Tanguay PL, Hardy MP, Caron E, de Verteuil D, Meloche S, Perreault C (2009) ER stress affects processing of MHC class I-associated peptides. BMC Immunol 10:10

147. Zhu XM, Dong N, Wang YB, Zhang QH, Yu Y, Yao YM, Liang HP (2017c) The involvement of endoplasmic reticulum stress response in immune dysfunction of dendritic cells after severe thermal injury in mice. Oncotarget 8:9035-9052

148. O'Sullivan ST, O'Connor TP (1997) Immunosuppression following thermal injury: the pathogenesis of immunodysfunction. Br J Plast Surg 50:615-623

149. Solana R, Pawelec G (1998) Molecular and cellular basis of immunosenescence. Mech Ageing Dev 102:115-129

150. Frasca D, Blomberg BB (2016) Inflammaging decreases adaptive and innate immune responses in mice and humans. Biogerontology 17:7-19

151. Roder JC, Duwe AK, Bell DA, Singhal SK (1978) Immunological senescence. I. The role of suppressor cells. Immunology 35:837847

152. Singhal SK, Roder JC, Duwe AK (1978) Suppressor cells in immunosenescence. Fed Proc 37:1245-1252

153. Derhovanessian E, Solana R, Larbi A, Pawelec G (2008) Immunity, ageing and cancer. Immun Ageing 5:11

154. Krenzien F, ElKhal A, Quante M, Rodriguez Cetina Biefer H, Hirofumi U, Gabardi S, Tullius SG (2015) A rationale for age- 
adapted immunosuppression in organ transplantation. Transplantation 99:2258-2268

155. Ciabattini A, Nardini C, Santoro F, Garagnani P, Franceschi C, Medaglini D (2018) Vaccination in the elderly: the challenge of immune changes with aging. Semin Immunol 40:83-94

156. Cupit-Link MC, Kirkland JL, Ness KK, Armstrong GT, Tchkonia T, LeBrasseur NK, Armenian SH, Ruddy KJ, Hashmi SK (2017) Biology of premature ageing in survivors of cancer. ESMO Open 2:e00250

157. Wang M, Law ME, Castellano RK, Law BK (2018) The unfolded protein response as a target for anticancer therapeutics. Crit Rev Oncol Hematol 127:66-79

158. Verschoor CP, Johnstone J, Millar J, Dorrington MG, Habibagahi M, Lelic A, Loeb M, Bramson JL, Bowdish DM (2013) Blood $\mathrm{CD}^{+} 3^{+} \mathrm{HLA}^{-} \mathrm{DR}^{-}$myeloid-derived suppressor cells are increased with age and a history of cancer. J Leukoc Biol 93:633-637

159. Alves AS, Ishimura ME, Duarte YAO, Bueno V (2018) Parameters of the immune system and vitamin D levels in old individuals. Front Immunol 9:1122

160. Enioutina EY, Bareyan D, Daynes RA (2011) A role for immature myeloid cells in immune senescence. J Immunol 186:697-707

161. Flores RR, Clauson CL, Cho J, Lee BC, McGowan SJ, Baker DJ, Niedernhofer LJ, Robbins PD (2017) Expansion of myeloidderived suppressor cells with aging in the bone marrow of mice through a NF-KB-dependent mechanism. Aging Cell 16:480-487

162. Ruhland MK, Loza AJ, Capietto AH, Luo X, Knolhoff BL, Flanagan KC, Belt BA, Alspach E, Leahy K, Luo J, Schaffer A, Edwards JR, Longmore G, Faccio R, DeNardo DG, Stewart SA (2016) Stromal senescence establishes an immunosuppressive microenvironment that drives tumorigenesis. Nat Commun 7:11762

163. Gregg R, Smith CM, Clark FJ, Dunnion D, Khan N, Chakraverty R, Nayak L, Moss PA (2005) The number of human peripheral blood $\mathrm{CD} 4^{+} \mathrm{CD} 25^{\text {high }}$ regulatory $\mathrm{T}$ cells increases with age. Clin Exp Immunol 140:540-546

164. Sharma S, Dominguez AL, Lustgarten J (2006) High accumulation of $\mathrm{T}$ regulatory cells prevents the activation of immune responses in aged animals. J Immunol 177:8348-8355

165. Jagger A, Shimojima Y, Goronzy JJ, Weyand CM (2014) Regulatory $\mathrm{T}$ cells and the immune aging process: a mini-review. Gerontology 60:130-137

166. Bapat SP, Myoung Suh J, Fang S, Liu S, Zhang Y, Cheng A, Zhou C, Liang Y, LeBlanc M, Liddle C, Atkins AR, Yu RT, Downes M, Evans RM, Zheng Y (2015) Depletion of fat-resident Treg cells prevents age-associated insulin resistance. Nature 528:137-141

167. Agius E, Lacy KE, Vukmanovic-Stejic M, Jagger AL, Papageorgiou AP, Hall S, Reed JR, Curnow SJ, FuentesDuculan J, Buckley CD, Salmon M, Taams LS, Krueger J, Greenwood J, Klein N, Rustin MH, Akbar AN (2009) Decreased TNF- $\alpha$ synthesis by macrophages restricts cutaneous immunosurveillance by memory $\mathrm{CD} 4+\mathrm{T}$ cells during aging. $\mathrm{J}$ Exp Med 206:1929-1940

168. Lumeng CN, Liu J, Geletka L, Delaney C, Delproposto J, Desai A, Oatmen K, Martinez-Santibanez G, Julius A, Garg S, Yung RL (2011) Aging is associated with an increase in T cells and inflammatory macrophages in visceral adipose tissue. J Immunol 187: 6208-6216

169. Jackaman C, Radley-Crabb HG, Soffe Z, Shavlakadze T, Grounds MD, Nelson DJ (2013) Targeting macrophages rescues agerelated immune deficiencies in $\mathrm{C} 57 \mathrm{BL} / 6 \mathrm{~J}$ geriatric mice. Aging Cell 12:345-357

170. Agrawal A, Gupta S (2011) Impact of aging on dendritic cell functions in humans. Ageing Res Rev 10:336-345

171. Hazeldine J, Lord JM (2013) The impact of ageing on natural killer cell function and potential consequences for health in older adults. Ageing Res Rev 12:1069-1078
172. Navarro V, Sanchez-Mejias E, Jimenez S, Munoz-Castro C, Sanchez-Varo R, Davila JC, Vizuete M, Gutierrez A, Vitorica J (2018) Microglia in Alzheimer's disease: Activated, dysfunctional or degenerative. Front Aging Neurosci 10:140

173. DiCarlo G, Wilcock D, Henderson D, Gordon M, Morgan D (2001) Intrahippocampal LPS injections reduce $A \beta$ load in APP+PS1 transgenic mice. Neurobiol Aging 22:1007-1012

174. Shaftel SS, Kyrkanides S, Olschowka JA, Miller JN, Johnson RE, O'Banion MK (2007) Sustained hippocampal IL-1 $\beta$ overexpression mediates chronic neuroinflammation and ameliorates Alzheimer plaque pathology. J Clin Invest 117:1595-1604

175. Wyss-Coray T, Masliah E, Mallory M, McConlogue L, JohnsonWood K, Lin C, Mucke L (1997) Amyloidogenic role of cytokine TGF- $\beta 1$ in transgenic mice and in Alzheimer's disease. Nature 389:603-606

176. Chakrabarty P, Li A, Ceballos-Diaz C, Eddy JA, Funk CC, Moore B, DiNunno N, Rosario AM, Cruz PE, Verbeeck C, Sacino A, Nix S, Janus C, Price ND, Das P, Golde TE (2015) IL-10 alters immunoproteostasis in APP mice, increasing plaque burden and worsening cognitive behavior. Neuron 85:519-533

177. Cherry JD, Olschowka JA, O'Banion MK (2014) Neuroinflammation and M2 microglia: the good, the bad, and the inflamed. J Neuroinflammation 11:98

178. Weekman EM, Sudduth TL, Abner EL, Popa GJ, Mendenhall MD, Brothers HM, Braun K, Greenstein A, Wilcock DM (2014) Transition from an M1 to a mixed neuroinflammatory phenotype increases amyloid deposition in APP/PS1 transgenic mice. J Neuroinflammation 11:127

179. Wang YW, Zhou Q, Zhang X, Qian QQ, Xu JW, Ni PF, Qian YN (2017) Mild endoplasmic reticulum stress ameliorates lipopolysaccharide-induced neuroinflammation and cognitive impairment via regulation of microglial polarization. J Neuroinflammation 14:233

180. Saresella M, Calabrese E, Marventano I, Piancone F, Gatti A, Calvo MG, Nemni R, Clerici M (2010) PD1 negative and PD1 positive $\mathrm{CD}^{+} \mathrm{T}$ regulatory cells in mild cognitive impairment and Alzheimer's disease. J Alzheimers Dis 21:927-938

181. Di Benedetto G, Burgaletto C, Carta AR, Saccone S, Lempereur L, Mulas G, Loreto C, Bernardini R, Cantarella G (2019) Beneficial effects of curtailing immune susceptibility in an Alzheimer's disease model. J Neuroinflammation 16:166

182. Thome AD, Faridar A, Beers DR, Thonhoff JR, Zhao W, Wen S, Pascual B, Masdeu JC, Appel SH (2018) Functional alterations of myeloid cells during the course of Alzheimer's disease. Mol Neurodegener 13:61

183. Baruch K, Rosenzweig N, Kertser A, Deczkowska A, Sharif AM, Spinrad A, Tsitsou-Kampeli A, Sarel A, Cahalon L, Schwartz M (2015) Breaking immune tolerance by targeting Foxp3+ regulatory T cells mitigates Alzheimer's disease pathology. Nat Commun 6:7967

184. Salminen A, Kaarniranta K, Kauppinen A (2018) The potential importance of myeloid-derived suppressor cells (MDSCs) in the pathogenesis of Alzheimer's disease. Cell Mol Life Sci 75:3099 3120

185. Motallebnezhad M, Jadidi-Niaragh F, Qamsari ES, Bagheri S, Gharibi T, Yousefi M (2016) The immunobiology of myeloidderived suppressor cells in cancer. Tumour Biol 37:1387-1406

186. Kwak Y, Kim HE, Park SG (2015) Insights into myeloid-derived suppressor cells in inflammatory diseases. Arch Immunol Ther Exp (Warsz) 63:269-285

187. Salminen A, Kaarniranta K, Kauppinen A (2019) Immunosenescence: the potential role of myeloid-derived suppressor cells (MDSC) in age-related immune deficiency. Cell Mol Life Sci 76:1901-1918 
188. Salminen A, Kauppinen A, Kaarniranta K (2018) Myeloidderived suppressor cells (MDSC): an important partner in cellular/tissue senescence. Biogerontology 19:325-339

189. Zhang Y, Alexander PB, Wang XF (2017) TGF- $\beta$ family signaling in the control of cell proliferation and survival. Cold Spring Harb Perspect Biol 9:a022145

190. Pohlers D, Brenmoehl J, Löffler I, Müller CK, Leipner C, Schultze-Mosgau S, Stallmach A, Kinne RW, Wolf G (2009) TGF- $\beta$ and fibrosis in different organs - molecular pathway imprints. Biochim Biophys Acta 1792:746-756

191. Kropski JA, Blackwell TS (2018) Endoplasmic reticulum stress in the pathogenesis of fibrotic disease. J Clin Invest 128:64-73

192. Cho N, Razipour SE, McCain ML (2018) Featured Article: TGF$\beta 1$ dominates extracellular matrix rigidity for inducing differentiation of human cardiac fibroblasts to myofibroblasts. Exp Biol Med (Maywood) 243:601-612

193. Ignotz RA, Massague J (1986) Transforming growth factor- $\beta$ stimulates the expression of fibronectin and collagen and their incorporation into the extracellular matrix. J Biol Chem 261: 4337-4345

194. Narola J, Pandey SN, Glick A, Chen YW (2013) Conditional expression of TGF- $\beta 1$ in skeletal muscles causes endomysial fibrosis and myofibers atrophy. PLoS One 8:e79356

195. Tominaga K, Suzuki HI (2019) TGF- $\beta$ signaling in cellular senescence and aging-related pathology. Int J Mol Sci 20:5002

196. Senturk S, Mumcuoglu M, Gursoy-Yuzugullu O, Cingoz B, Akcali KC, Ozturk M (2010) Transforming growth factor- $\beta$ induces senescence in hepatocellular carcinoma cells and inhibits tumor growth. Hepatology 52:966-974

197. Frippiat C, Chen QM, Zdanov S, Magalhaes JP, Remacle J, Toussaint O (2001) Subcytotoxic H2O2 stress triggers a release of transforming growth factor- $\beta 1$, which induces biomarkers of cellular senescence of human diploid fibroblasts. J Biol Chem 276:2531-2537

198. Vijayachandra K, Higgins W, Lee J, Glick A (2009) Induction of p16ink4a and p19ARF by TGF $\beta 1$ contributes to growth arrest and senescence response in mouse keratinocytes. Mol Carcinog 48: $181-186$
199. Corzo CA, Cotter MJ, Cheng P, Cheng F, Kusmartsev S, Sotomayor E, Padhya T, McCaffrey TV, McCaffrey JC, Gabrilovich DI (2009) Mechanism regulating reactive oxygen species in tumor-induced myeloid-derived suppressor cells. J Immunol 182:5693-5701

200. McGaha TL, Huang L, Lemos H, Metz R, Mautino M, Prendergast GC, Mellor AL (2012) Amino acid catabolism: a pivotal regulator of innate and adaptive immunity. Immunol Rev 249:135-157

201. Murray PJ (2016) Amino acid auxotrophy as a system of immunological control nodes. Nat Immunol 17:132-139

202. Castilho BA, Shanmugam R, Silva RC, Ramesh R, Himme BM, Sattlegger E (2014) Keeping the eIF2 $\alpha$ kinase Gcn2 in check. Biochim Biophys Acta 1843:1948-1968

203. Rath M, Müller I, Kropf P, Closs EI, Munder M (2014) Metabolism via arginase or nitric oxide synthase: Two competing arginine pathways in macrophages. Front Immunol 5:532

204. Chen Y, Guillemin GJ (2009) Kynurenine pathway metabolites in humans: disease and healthy states. Int J Tryptophan Res 2:1-19

205. Valerio A, Nisoli E (2015) Nitric oxide, interorganelle communication, and energy flow: a novel route to slow aging. Front Cell Dev Biol 3:6

206. Kan MJ, Lee JE, Wilson JG, Everhart AL, Brown CM, Hoofnagle AN, Jansen M, Vitek MP, Gunn MD, Colton CA (2015) Arginine deprivation and immune suppression in a mouse model of Alzheimer's disease. J Neurosci 35:5969-5982

207. van der Goot AT, Nollen EA (2013) Tryptophan metabolism: entering the field of aging and age-related pathologies. Trends Mol Med 19:336-344

208. Wu W, Nicolazzo JA, Wen L, Chung R, Stankovic R, Bao SS, Lim CK, Brew BJ, Cullen KM, Guillemin GJ (2013) Expression of tryptophan 2,3-dioxygenase and production of kynurenine pathway metabolites in triple transgenic mice and human Alzheimer's disease brain. PLoS One 8:e59749

Publisher's note Springer Nature remains neutral with regard to jurisdictional claims in published maps and institutional affiliations. 